INEEL/EXT-97/01032

\title{
Buried Waste Containment System Materials Final Report
}

J. R. Weidner

P. G. Shaw

Published October 1997

Idaho National Engineering and Environmental Laboratory

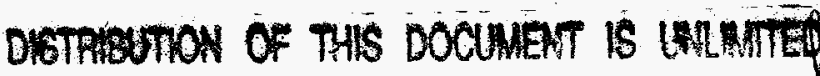

Lockheed Martin Idaho Technologies Company

Environmental Restoration Technologies Department

Idaho Falls, Idaho 83415

Prepared for the

U.S. Department of Energy

Assistant Secretary for Environmental Management

Under DOE Idaho Operations Office

Contract DE-AC07-94ID13223 


\section{DISCLAIMER}

This report was prepared as an account of work sponsored by an agency of the United States Government. Neither the United States Government nor any agency thereof, nor any of their employees, make any warranty, express or implied, or assumes any legal liabiity or responsibility for the accuracy, completeness, or usefulness of any information, apparatus, product, or process disclosed, or represents that its use would not infringe privately owned rights. Reference herein to any specific commercial product, process, or service by trade name, trademark, manufacturer, or otherwise does not necessarily constitute or imply its endorsement, recommendation, or favoring by the United States Government or any agency thereof. The views and opinions of authors expressed herein do not necessarily state or reflect those of the United States Government or any agency thereof. 


\section{DISCLAIMER}

Portions of this document may be illegible electronic image products. Images are produced from the best available original document. 


\section{ABSTRACT}

This report describes the results of a test program to validate the application of a latex-modified cement formulation for use with the Buried Waste

Containment System (BWCS) process during a proof-of-principle demonstration. 



\section{EXECUTIVE SUMMARY}

The primary objectives of the BWCS materials program include validation of the barrier material formulation, determination of the effect of the barrier emplacement process on the barrier material properties, and measurement of the hydraulic properties of a stop-start joint.

The results of the program indicate that:

1. The optimum barrier material compositions for the required set time and compressive strength were in the range 100 parts Rapid Set $\circledast$ cement to 200 to 300 parts ASTM C 33 sand, 35 to 50 parts water, 15 parts latex (solids, Modifier A, Dow Chemical) and 0.4 to 0.7 parts citric acid.

2. Water in solutions saturated with calcite (carbonate), gypsum (sulfate), test site leachate, and distilled water caused a reduction in compressive strength of about $30 \%$ for laboratory-prepared samples and $45 \%$ for field core samples. The carbonate, sulfate, and test site soil leachates had no apparent effect, other than the effect of water. The loss of strength due to water immersion is typical of latex-modified mortar and concrete. The loss of strength is usually accompanied by water absorption by the latex and a very beneficial decrease in hydraulic conductivity of the material. The changes are thought to be reversible, that is, the sample strength returns, the latex shrinks, etc., as the water is lost. The decrease in compressive strength may be beneficial for the BWCS application provided that other properties are not degraded, particularly an increase in barrier permeability. The decrease in compressive strength may indicate an increase in the ability of the material to deform without fracture, i.e., the material becomes less brittle and less likely to crack.

3. Differences in mixing procedures and curing environments caused significant differences in the properties of the field samples compared to laboratory baseline samples, namely compressive strength-5,241 psi (field) compared to $1,861 \mathrm{psi}$; modules of elasticity $-2,970,000 \mathrm{psi}$ (field) versus $403,000 \mathrm{psi}$; tensile strength-200 psi (field) versus 143 psi; and specific gravity -2.19 (field) versus 1.93 . The flexural strength is about the same-604 psi (field) versus $688 \mathrm{psi}$. The differences in properties are probably due to differences in material preparation procedures and curing environment. These differences are thought to be due primarily to three factors. The different methods used to mix the two materials may have resulted in different air contents (void spaces). The baseline material did not appear to cure to the same degree as the field materials over the same time periods, which may be due to differences in temperature and humidity during the curing process and to a difference in the order of introducing the components into the mixtures, particularly a possible reaction between the latex and citric acid during the preparation of the baseline materials. Data indicate that the properties of the baseline barrier material are identical to the properties of the field test material provided that the citric acid and latex are not allowed to interact during mixture preparation. 
4. The laboratory-measured hydraulic conductivity of the field test barrier material, both with and without a stop-start joint, exceeded the EPA $1 \times 10^{-7} \mathrm{~cm} / \mathrm{s}$ requirement for hazardous waste sites. The values are $1.1 \times 10^{-8} \mathrm{~cm} / \mathrm{s}$ for the stop-start joint and $1.6 \times 10^{-10} \mathrm{~cm} / \mathrm{s}$ for the homogeneous field test material. These results were confirmed by less precise air permeability measurements, which indicated hydraulic conductivities of $8.6 \times 10^{-7} \mathrm{~cm} / \mathrm{s}$ (stop-start joint) and $8.6 \times 10^{-9} \mathrm{~cm} / \mathrm{s}$ (homogeneous barrier material).

Detailed examination of the field test slab showed only a single defect, a hairline fracture in the center section between two stop-start joints. The cause of the fracture is not apparent from available data. Virtually identical procedures and materials were used to produce a slab containing two stop-start joints during the BWCS visual test (see Reference 8), but this slab did not fracture. The hydraulic conductivity of material containing the fracture was low, $1.2 \times 10^{-5}$ $\mathrm{cm} / \mathrm{s}$.

In general, the test results indicate that the latex-modified cement barrier material is satisfactory for the BWCS application in an arid environment. However it is recommended that several aspects of the material be systematically investigated. These include the following:

1. The effect of water on the short- and long-term durability of the barrier material, particularly hydraulic conductivity and susceptibility to fracture formation, should be determined. This includes experiments to determine the long-term alteration mechanisms and the rate of alteration and mass loss and the effect on hydraulic conductivity and other properties. The decrease in compressive strength may be beneficial for the BWCS application as it probably also produces an increase in plasticity and a decrease in fracture formation in the barrier material. This hypothesis needs to be tested and the relationships with other properties of the material evaluated.

2. The limiting water content of the waste site soil, which would allow for the set and cure of the barrier material, should be determined. The results would indicate applications near or below the water table and in non-arid climates.

3. The optimum barrier material composition to minimize or eliminate fracture formation should be determined. This suggestion comes from the observation of the hairline fracture, which formed in BWCS Test Run \#2. The cause of the fracture is not apparent from available data. Virtually identical procedures and materials were used to produce a test slab containing two stop-start joints during the BWCS visual test (see Reference 8), but this test slab did not fracture. Systematic work needs to be done to identify and eliminate the factors that cause cracking while not adversely affecting the required properties of the material.

4. The barrier material composition and emplacement procedure should be developed to optimize stop-start joint properties, particularly hydraulic conductivity and strength.

5. In general, the long-term durability of the material needs to be evaluated and, if necessary, the composition optimized for best performance. Two topics 
need particular attention. At present, no information is available to estimate the resistance of the barrier materials to biological degradation. Therefore, a systematic study of biological degradation needs to be carried out. A second aspect of long-term durability is the development of means to prevent mechanical stress and the resulting long-term development of fractures in the barrier material. An approach should be developed to optimize the material's resistance to stress and to also minimize the stress to which the material will be subjected.

6. The barrier material composition should be evaluated and optimized for application at the specific waste site. Waste site properties to be considered include, but are not limited to, waste composition, soil chemistry and water content, and site geology including seismic activity, climate, and other properties. 



\section{CONTENTS}

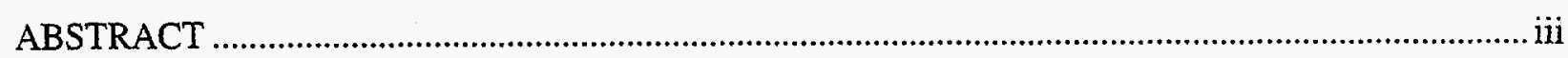

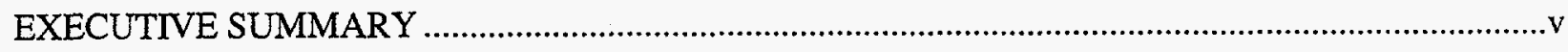

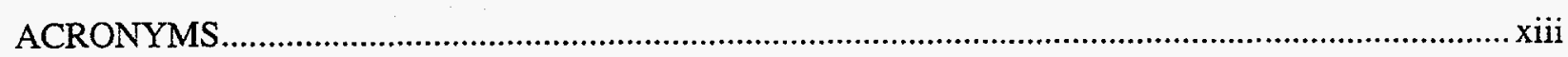

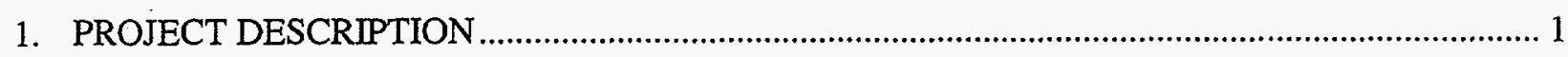

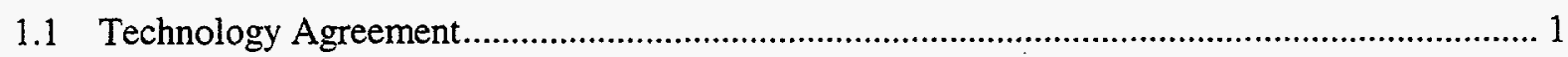

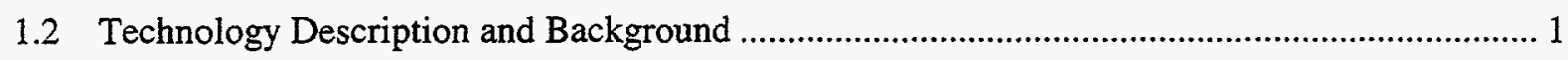

1.2.1 Test Program Scope.............................................................................................. 1

1.2.2 BWCS Description and Barrier Material Application Requirements ............................. 1

1.2.3 Barrier Material Durability Properties ........................................................................ 2

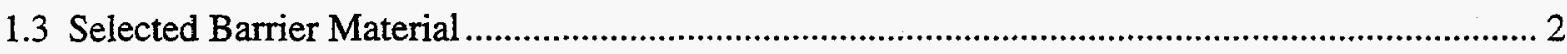

2. LABORATORY MATERIAL VALIDATION MEASUREMENT .................................................. 3

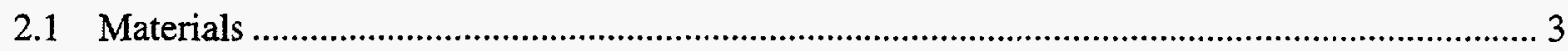

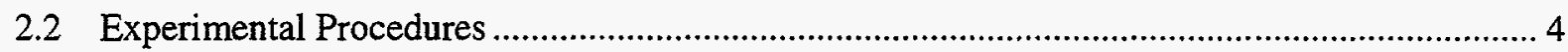

2.2.1 Laboratory Barrier Material Preparation ............................................................................ 4

2.2.2 Viscosity, Compressive Strength, Slump, and Temperature Measurements ..................... 5

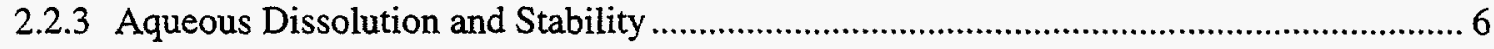

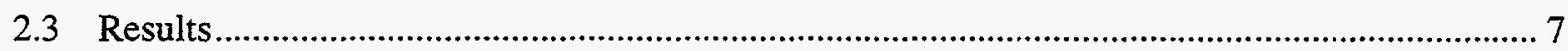

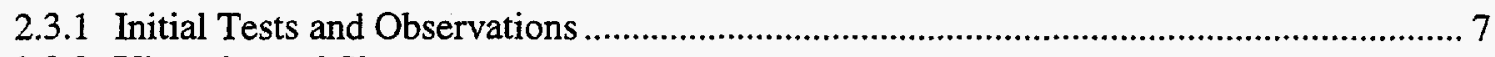

2.3.2 Viscosity and Slump................................................................................................ 7

2.3.3 Workability Time, Set Time, and Composition ......................................................... 8

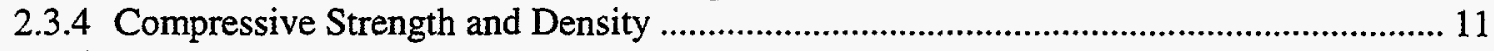

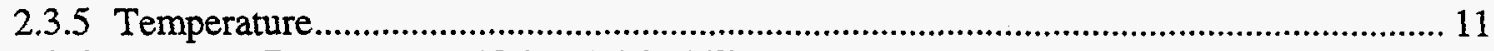

2.3.6 Aqueous Treatment and Material Stability ............................................................ 16

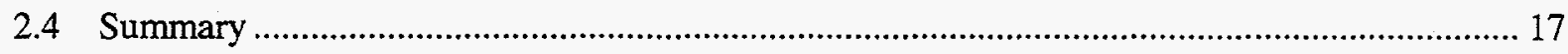

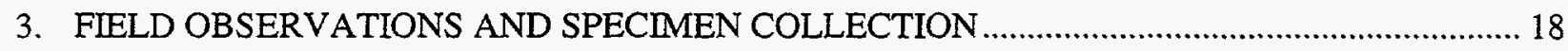

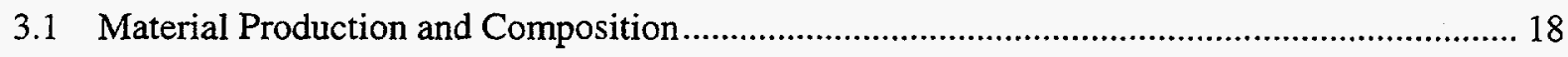

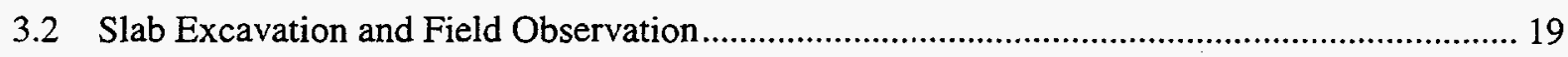

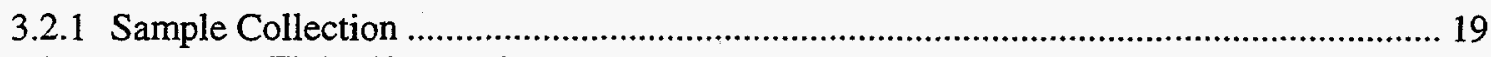

3.2.2 Summary Field Observations ….................................................................................... 19 


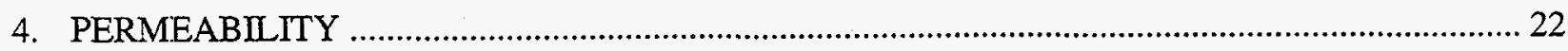

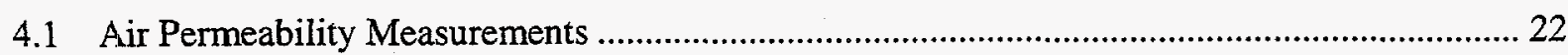

4.1.1 Air Permeability Field Method and Observations........................................................... 23

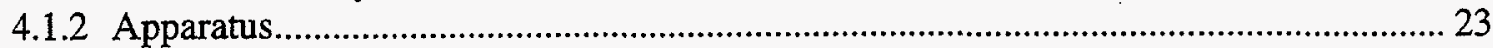

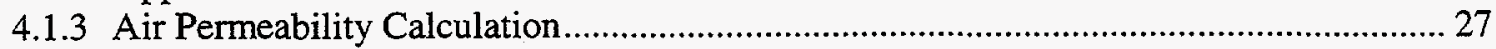

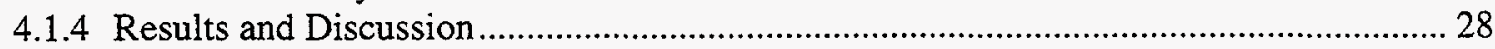

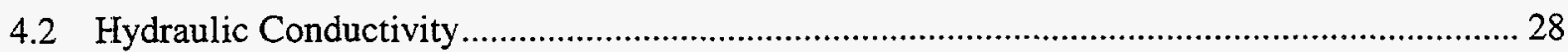

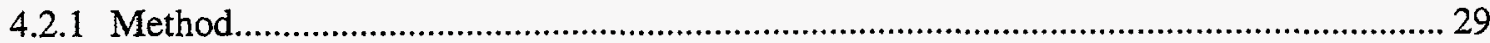

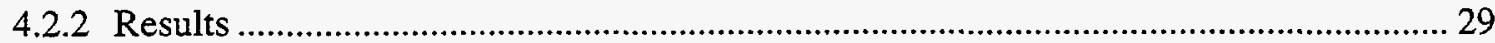

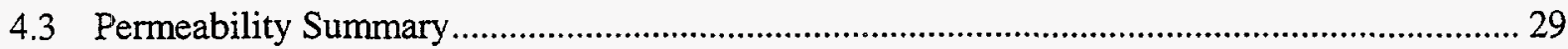

5. MECHANICAL PROPERTIES OF FIELD AND BASELINE BARRIER MATERIAL ................... 30

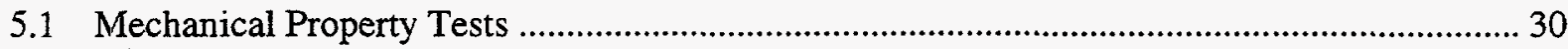

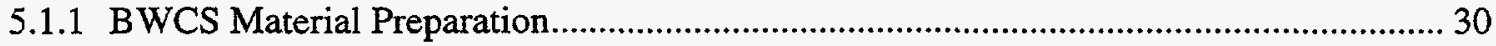

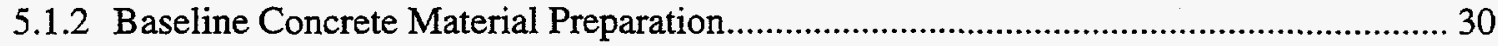

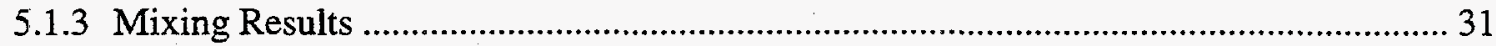

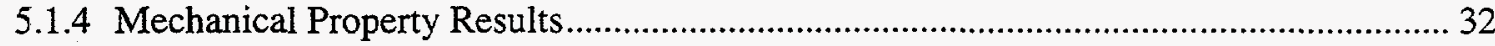

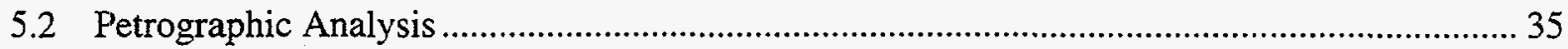

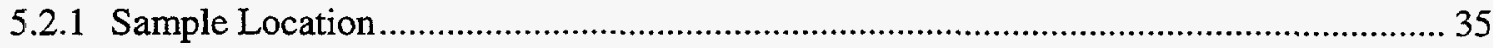

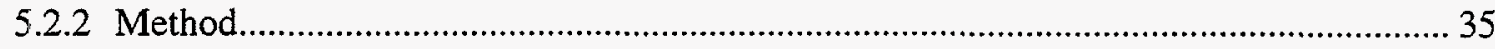

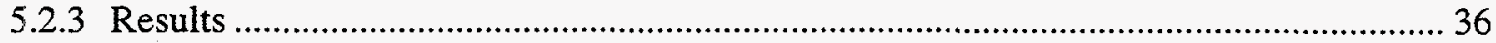

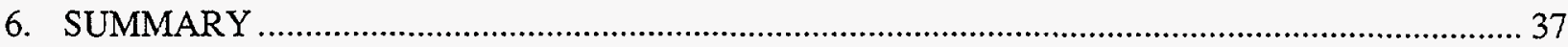

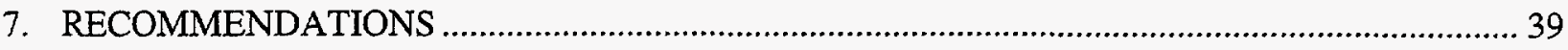

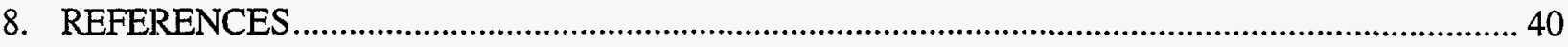

Appendix A - Equipment

Appendix B - Baseline Sample Mixture \#3 


\section{FIGURES}

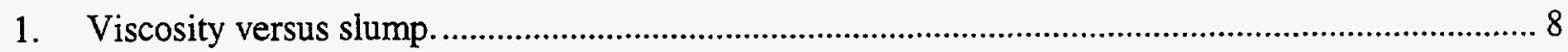

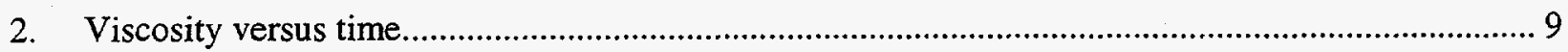

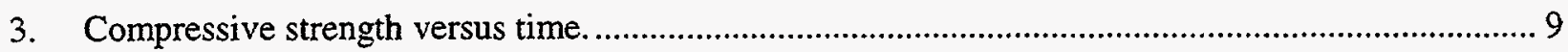

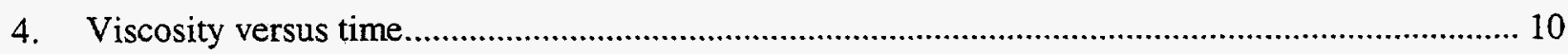

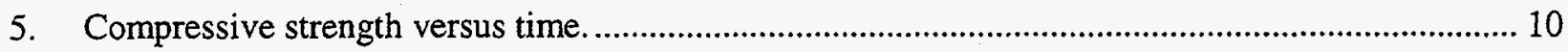

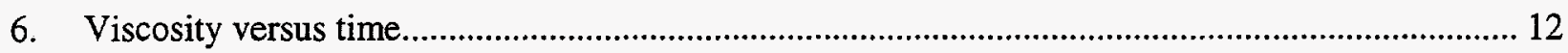

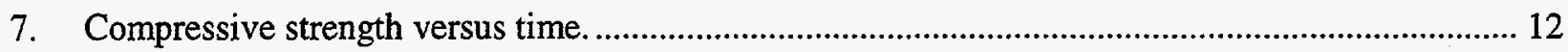

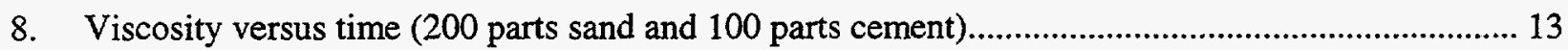

9. Cmpressive strength versus time (200 parts sand and 100 parts cement)...................................... 13

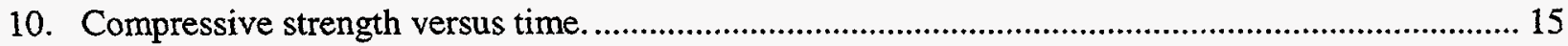

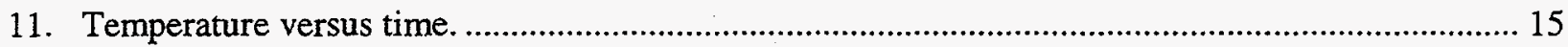

12. Hairline fracture in BWCS Test Run \#2. Fracture highlighted with water for greater visibility..... 20

13. Core hole across the hairline fracture. Fracture highlighted with water for greater visibility......... 20

14. Core containing the hairline fracture. Fracture highlighted with water for greater visibility........... 21

15. End of the core containing the hairline fracture. Fracture highlighted with water for greater visibility.

16. Core containing the stop-start joint. The joint interface is the surface between the white and red material.

17. Air permeability cell in the open position so that sealant is not squeezed from between end plates during insertion of cell into test hole

18. Air permeability cell in the closed position to squeeze sealant from between end plates.

19. Air permeability cell in operating position in the BWCS Test Run $\# 2$ test slab. 26

20. Air permeability cell instrumentation and layout. 


\section{TABLES}

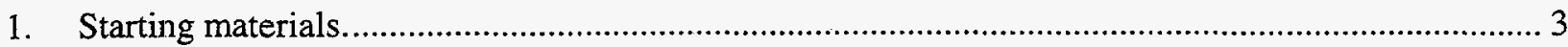

2. Composition ranges for laboratory BWCS material. ................................................................... 4

3. Composition and physical characteristics of the 2-to-1 sand-to-cement mixtures......................... 14

4. Composition and physical characteristics of several sand-to-cement ratios................................ 14

5. Results of aqueous treatment of laboratory-molded and field core cylinders................................ 17

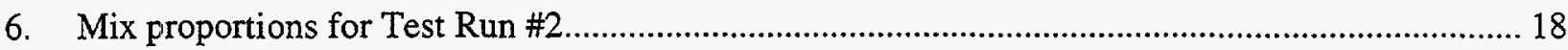

7. Permeability and hydraulic conductivity results from air permeability....................................... 28

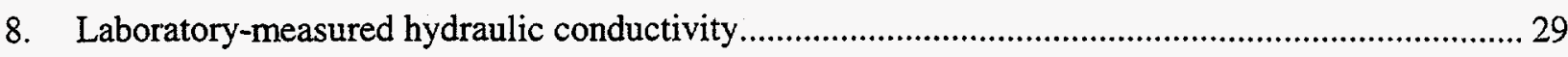

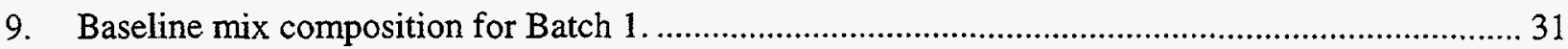

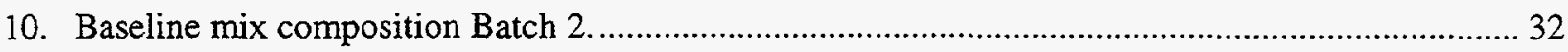

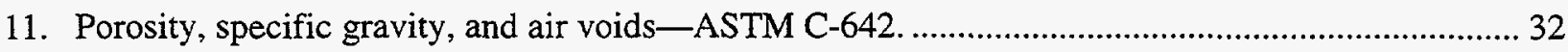

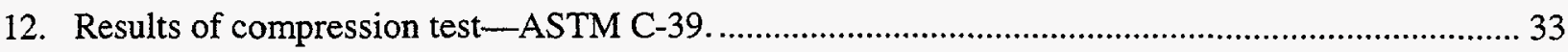

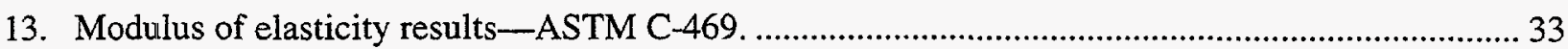

14. Results of tensile strength test (splitting strength)_ASTM C-496............................................ 33

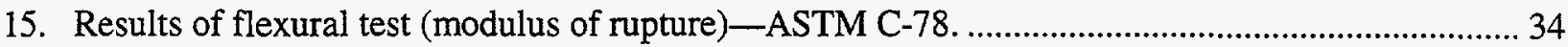

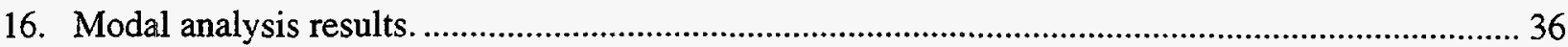




\section{ACRONYMS}

ASTM American Society of Testing and Materials

BWCS Buried Waste Containment System

DI deionized

EPA U.S. Environmental Protection Agency

INEEL Idaho National Engineering and Environmental Laboratory

k hydraulic conductivity

MTL Materials Testing Laboratory

$\mathrm{pH} \quad$ negative logarithm of hydrogen activity

POP proof of principle

psi pounds per square inch

RAHCO R. A. Hanson Company, International

SBR styrene butadiene rubber

SSD saturated surface dry

W/C water-to-cement ratio 


\section{BURIED WASTE CONTAINMENT SYSTEM MATERIALS FINAL REPORT}

\section{PROJECT DESCRIPTION}

\subsection{Technology Agreement}

The laboratory testing of the barrier materials to support the Buried Waste Containment System (BWCS) program was performed under TTP-ID-77SS21.

\subsection{Technology Description and Background}

\subsubsection{Test Program Scope}

This report describes the results of a test program to validate the application of a latex-modified cement formulation for use with the BWCS process during a proof of principle (POP) demonstration.

The test program included three objectives. One objective was to validate the barrier material mix formulation to be used with the BWCS equipment. A basic mix formula for initial trials was supplied by the cement and latex vendors. The suitability of the material for BWCS application was verified by laboratory testing at the Idaho National Engineering and Environmental Laboratory (INEEL). A second objective was to determine if the POP BWCS material emplacement process adversely affected the barrier material properties. This objective was met by measuring and comparing properties of material prepared in the INEEL Materials Testing Laboratory (MTL) with identical properties of material produced by the BWCS field tests. These measurements included hydraulic conductivity to determine if the material met the U.S. Environmental Protection Agency (EPA) requirements for barriers used for hazardous waste sites, ${ }^{1}$ petrographic analysis to allow an assessment of barrier material separation and segregation during emplacement, and a set of mechanical property tests typical of concrete characterization. The third objective was to measure the hydraulic properties of barrier material containing a stop-start joint to determine if such a feature would meet the EPA requirements for hazardous waste site barriers.'

\subsubsection{BWCS Description and Barrier Material Application Requirements}

The BWCS is a technology for the in situ fabrication of a trough-shaped waste containment barrier beneath a waste site. The bottom of the trough would be about $40 \mathrm{ft}$ wide and have a thickness of $1 \mathrm{ft}$. The depth to the trough bottom would be $20 \mathrm{ft}$. The trough sides would be vertical or sloped outward and have a thickness of about 6 in. The trough material is to provide an impermeable barrier to contaminant migration; therefore, the material must have virtually zero crack density at the field scale and a hydraulic conductivity of $1 \times 10^{-7} \mathrm{~cm} / \mathrm{s}$ or less as measured in the laboratory. The shape of the structure and the low crack density require the material to either have very small volume change during set and cure or be capable of some plastic deformation without cracking. The BWCS process and placement equipment also impose some constraints on the physical properties of the material and the setting process.

The requirement for the initial set time is 15 minutes minimum to 30 minutes maximum, and is the time required to develop a compressive strength of 20 psi.

The compressive strength (ASTM C 39) ${ }^{2}$ at set must exceed 20 psi to support the soil overburden during the grouting process. This number is a conservative estimate based on an assumed soil 
overburden density of $1.6 \mathrm{~g} / \mathrm{cm}^{3}$. The load produced by the overburden at a depth of $20 \mathrm{ft}$ would then be about 14 psi. In the case of buried waste typical of the INEEL Radioactive Waste Management Complex, the average density would be reduced from the assumed $1.6 \mathrm{~g} / \mathrm{cm}^{3}$ to $1.2 \mathrm{~g} / \mathrm{cm}^{3}$ (see Reference 3). The phrase "initial set time" as used in this report is that time at which the cement mixture achieves a compressive strength of 20 psi.

- Maximum set temperature is to be less than $100^{\circ} \mathrm{C}$.

- Slump (ASTM C 143) is to be 8 to $10 \mathrm{in.}$

- Aggregate particle size must be in accordance with ASTM C 33 for fine aggregate.

\subsubsection{Barrier Material Durability Properties}

The barrier material will be applied to a waste site in an arid environment and should have chemical properties that are compatible with the soil and groundwater typical of arid climates. Therefore, the barrier material must be:

- Resistant to chemical attack in solutions saturated with calcite- $-\mathrm{CaCO}_{3}$ (high carbonate) and gypsum- $\mathrm{CaSO}_{4} \cdot 2 \mathrm{H}_{2} \mathrm{O}$ (high sulfate), typical of caliche deposits in arid region soils.

- Resistant to chemical attack in contact with solutions extracted from the waste site soil.

\subsection{Selected Barrier Material}

Rapid Set $\AA^{a}$ cement-based mortar, modified with latex (i.e., styrene butadiene rubber) was selected as the most reasonable candidate material for the BWCS POP application. The styrene butadiene rubber (SBR) material is a commercially available commodity used in the construction industry and has also been tested for waste barrier applications. ${ }^{4}$ The latex provides low-permeability, high-adhesion resistance to chemical attack, as well as resilience and resistance to crack formation. Rapid Set cement, a proprietary material manufactured by the CTS Cement Manufacturing Company, was chosen because it is sulfate-resistant, has minimal shrinkage, a set time less than 30 minutes without the addition of special accelerators, and has been tested with the SBR admixture. Latex-modified cement was preferred for this application because it has workability properties similar to conventional cement, is hazard free and environmentally safe, is easily cleaned up with water, and is expected to have satisfactory long-term durability properties. ${ }^{4}$

Taken together, the properties of the latex-modified Rapid Set mortar indicate an adequate barrier material for use in arid environments at a cost lower than barrier materials requiring two components or hazardous constituents.

a. References herein to any specific commercial product, process, or service by trade name, trademark, manufacturer, or otherwise, does not necessarily constitute or imply its endorsement, recommendations, or favoring by the United States Government or any agency thereof. 


\section{LABORATORY MATERIAL VALIDATION MEASUREMENT}

The laboratory material validation measurements and experiments were made up of three sets of tests. The first set included several experiments to gain experience working with latex-modified Rapid Set cement and to determine if these materials would be suitable for the BWCS application. The second set of measurements was a quantitative examination of the factors such as batch set time, viscosity, slump, composition, and temperature affecting mixture performance in order to verify a barrier material formulation that would meet the BWCS requirements. The third set of measurements was a series of simple experiments to assess the effect of carbonate, sulfate, and test site soil leachates on the compressive strength of the barrier material.

Mixture compositions are often referred to in terms of "parts," as in "35 parts water" or "0.7 parts citric acid." This is the amount of the particular component compared to 100 parts cement by weight.

\subsection{Materials}

Standard equipment was used for the laboratory test program (see Appendix A). The materials used in the test program are listed in Table 1 . The following paragraphs describe these materials.

Rapid Set cement is a hydraulic cement manufactured by the CTS Cement Manufacturing Company. It is used in industry for applications such as bridge overlays and airport runway repair where high early strength and very low shrinkage are required. It is resistant to sulfate attack. Rapid Set cement was used to prepare all the materials discussed in this report, including field test and baseline tests as well as the laboratory test discussed here.

The latex cement additive, Modifier A, was manufactured by the Dow Chemical Company. Modifier A is a white liquid emulsion of SBR and other materials and has about $48 \mathrm{wt} \%$ solids. The latex provides low-permeability, high-adhesion resistance to chemical attack and crack formation. Latex Modifier A was the latex used in all materials discussed in this report, including field tests, baseline tests, and laboratory tests.

The sand used in most laboratory mixtures met the specification for concrete sand, ASTM C-33. In some initial laboratory tests, mortar sand, meeting specification ASTM C-144, was also used. The size specification for both sand lots was verified by sieving in the INEEL laboratory. The concrete sand contained $4 \pm 1 \mathrm{wt} \%$ water; the mortar sand contained $2.5 \pm 1 \mathrm{wt} \%$ water and was determined by weight loss at $105^{\circ} \mathrm{C}$.

Citric acid, used as a set retardant, was a reagent-grade, solid material supplied by Fisher Scientific. The citric acid was always mixed with the cement prior to the addition of the latex in order to prevent an undesirable reaction between the basic latex and the acid.

Table 1. Starting materials.

\begin{tabular}{llc}
\hline \multicolumn{1}{c}{ Material } & \multicolumn{1}{c}{ Manufacturer } & $\begin{array}{c}\text { Specific } \\
\text { Gravity }\end{array}$ \\
\hline Rapid Set Cement & CTS Cement Manufacturing Company Inc. & 3.1 \\
Latex, Modifier A & Dow Chemical Co.; Lot No. LB20017323; ${ }^{\mathrm{a}}$ Lot No. LB230172120 & 1.04 \\
Sand & Burns Concrete, Inc.; ASTM C-33; ASTM C-144 & 2.5 \\
Citric Acid & Fisher Scientific, Reagent Grade Lot No. 897083 & 2.2 \\
& & \\
a. Latex lot used in INEEL Research Center laboratory mixtures. & \\
b. Latex lot used in INEEL Central Facilities Area baseline mixtures. & \\
\hline
\end{tabular}




\subsection{Experimental Procedures}

The objectives of the barrier material laboratory tests include the determination of temperatures during barrier material curing, mixture compositions so that set time was between 15 and 30 minutes and slump was between 8 and 10 in., viscosity of mixtures as a function of time, and aqueous dissolution and stability studies of barrier materials. Because of the fast reaction rates of the materials, special procedures had to be developed for some measurements. All the laboratory procedures are described in this section and were carried out at the INEEL Research Center.

\subsubsection{Laboratory Barrier Material Preparation}

The laboratory test materials were prepared according to the following procedures. The dry cement and citric acid were first mixed together followed by the sand, then latex, and finally water. The mixing order was used in order to achieve complete mixing of the materials in the shortest amount of time without neutralizing the citric acid with the latex. Note that citric acid is added to and reacts with the cement before the latex emulsion is added in order to minimize the acid-base reaction between citric acid and latex. Small samples, $1 \mathrm{~kg}$ or less, were mixed rapidly in plastic beakers by hand until homogenous. The larger samples were mixed in plastic buckets with a small shovel. A Hobart mechanical mixer was available, but not used because of the possibility of introducing too much air into the mixture. Where possible, techniques for mixing followed ASTM C-305, "Practice for Mechanical Mixing of Hydraulic Cement Pastes and Mortars of Plastic Consistency."2 Components in small batches, $1 \mathrm{~kg}$ or less, were weighed to the nearest $10 \mathrm{mg}$. Larger mixtures were weighed on a floor balance to the nearest $5 \mathrm{~g}$. Sixteen different formulations were used for laboratory testing. The range of compositions prepared is shown in Table 2.

Table 2. Composition ranges for laboratory BWCS material.

\begin{tabular}{|c|c|c|c|c|c|c|}
\hline & \multicolumn{2}{|c|}{ Low $^{\mathrm{a}}$} & \multicolumn{2}{|c|}{$\mathrm{High}^{\mathrm{b}}$} & \multicolumn{2}{|c|}{ Mode $^{c}$} \\
\hline & Parts $^{\mathrm{d}}$ & $\mathrm{wt} \%$ & Parts & $\mathrm{wt} \%$ & Parts & $\mathrm{wt} \%$ \\
\hline Cement & 100 & 18 & 100 & 59 & 100 & 28 \\
\hline Sand & 0 & 0 & 400 & 70 & 200 & 56 \\
\hline Latex $^{e}$ & 14 & 4 & 62 & 15 & 15 & 4.2 \\
\hline Water $^{\mathrm{f}}$ & 20 & 10 & 80 & 32 & 40 & 11.2 \\
\hline Citric acid & 0 & 0 & 1.5 & 0.4 & 0.7 & 0.2 \\
\hline \multicolumn{7}{|c|}{$\begin{array}{l}\text { a. Lowest percentage tested. } \\
\text { b. Highest percentage tested. } \\
\text { c. Most frequently tested composition. } \\
\text { d. Parts based on } 100 \text { parts cement. } \\
\text { e. Latex solids, } 47.74 \% \text { as supplied. } \\
\text { f. Total water. }\end{array}$} \\
\hline
\end{tabular}


After mixing, the test material was used for viscosity measurements or slump measurements, or was molded into cylinders. In many cases, the material used for viscosity or slump measurements was molded into test cylinders after the measurements were complete. Cylinder sizes (diameter versus length) included $0.5 \times 1$ in., $1 \times 2$ in., $2 \times 4$ in., and $3 \times 6$ in. A thin coat of silicon vacuum grease was used as a release agent on the walls of the plastic cylindrical molds. In general, the test specimens were removed from the molds when manually pressing on the barrier material no longer produced an indentation, usually within 30 minutes after sample preparation. In the case of the set time determinations, the test specimens were removed as soon as they appeared to be self supporting. Usually 10 to 24 cylinders were prepared from each batch of material.

\subsubsection{Viscosity, Compressive Strength, Slump, and Temperature Measurements}

2.2.2.1 Viscosity Measurements. The viscosity of the latex mortar material was measured as a function of time using a Brookfield Digital Viscometer, Model DVII+, equipped with a Brookfield Helipath Stand and a T-bar Spindle. Procedures followed the manufacturer's instructions, which were based on ASTM methods. Viscosity measurements were started as soon as the sample was mixed and visually determined to be homogeneous, usually within 2 minutes of the addition of water and latex. Mixture viscosity measurements were made using 80 to $120 \mathrm{~g} \mathrm{(40} \mathrm{to} 60 \mathrm{~mL})$ of material in a $100-\mathrm{mL}$ plastic beaker.

Timed data point collection was made using the Wingather software provided by the manufacturer. The time was measured starting at the instant of the addition of the latex/water to the mixture. Mixture temperature, viscosity, and spindle rotational speed were measured and electronically recorded at 2 -second intervals. When viscosity measurements reached 500,000 to a maximum of $1,000,000$ centipoise, viscosity measurements were stopped and the material was transferred into molds to produce tests specimens for compressive strength and other measurements. Because viscosity measurements required less than $100 \mathrm{~g}$ of material and were easily and quickly prepared, viscosity was routinely determined on all batches of material.

2.2.2.2 Compressive Strength and Density. Compressive strength was used to define initial set time, i.e., the time required to support a load of $20 \mathrm{psi}$, and also to provide an easily measured parameter to use as a monitor of barrier material change with time. Density was measured as part of the material characterization process.

Compressive strength was conducted according to ASTM C 39-96 and ASTM D-1633 except that $1 \times$ 2 -in. cylinders were sometimes used rather than the prescribed minimum $2 \times 4$-in cylinders. Previous testing at the INEEL indicated that measurement precision was unaffected by sample size for this type of sample. When necessary, $1 \times 2$-in. cylinders with broken or uneven ends were supported in plastic boats containing sand to compensate for the uneven surfaces.

Measurements were made with an ECS G-900 Versa-Loader equipped with a Soil Cement Test Digital Readout Set. The system has a $10,000-1 b$ capacity. Data were recorded manually from the digital readout system.

The compressive strength was measured by slowly compressing the cylindrical samples at a rate of $0.05 \mathrm{in} . / \mathrm{min}$. Pounds force was read on the factory-calibrated digital strain gauge. Typically, the exerted force increased gradually to a maximum, then fell of rapidly when the sample cracked. Irregularities of the sample shape or the presence of voids often produced multiple peaks or a very broad peak. This generally resulted in a lower maximum reading.

Two to six samples were used for the initial set time measurements. The remaining samples were stored in small, sealed, plastic bags. Systematic compressive strength measurements were made in the 
first hour, the first day, and then at 28 days after mixture preparation on most mixtures and 2 months on many of them. Compressive strength was measured 30 minutes after batch preparation to determine the initial set time. Density was measured according to ASTM C-642, "Porosity, Specific Gravity, and Air Voids."

2.2.2.3 Slump. Slump was determined according to ASTM C-143 using Slump Test Set CT-225 supplied by ELE International.

Slump was determined only on selected batches because slump measurements required at least $8 \mathrm{~kg}$ of material. Viscosity was determined simultaneously with slump, but using a separate sample from the same batch. Each slump test required about 3 to 5 minutes to perform and was repeated for a given batch of material until the slump measurement was less than 8 in., corresponding to a viscosity exceeding 500,000 centipoise. Each slump test was recorded manually as a function of time. Viscosity measurements were simultaneously recorded electronically.

2.2.2.4 Temperature Measurement. Temperature was determined during viscosity tests using the temperature probe attached to the viscometer and was recorded electronically using the Wingather software. Mixture temperature during the setting and curing process was determined using an ethanol thermometer imbedded in the center of a $3 \times 6$-in. cylinder filled with uncured barrier material. Temperature measurements were manually recorded as a function of time until the temperature peaked and began to drop.

\subsubsection{Aqueous Dissolution and Stability}

The barrier material will be applied to a waste site in an arid environment and therefore should have chemical properties that are compatible with the soil and groundwater typical of arid environments. The following experiments provide information about the behavior of the barrier materials in different aqueous environments.

Laboratory-molded $1 \times 2$-in. cylinders and $1.25 \times 2.5$-in. cores drilled from the BWCS buried Barrier Test \#2 flexural beam samples (see Section 5.1) were tested in three different aqueous solutions. One solution was saturated with respect to calcium carbonate, $\mathrm{CaCO}_{3}$, and calcium sulfate dihydrate, $\mathrm{CaSO}_{4} \cdot 2 \mathrm{H}_{2} \mathrm{O}$, to simulate the minerals calcite and gypsum, respectively. A second aqueous solution was saturated with respect to the soil, mineralogy unknown, from the RAHCO International $@$ test site in Spokane Washington. The third solution provided the experiment control and was distilled-deionized (DI) water. A fourth set of samples were left untreated as a standard of comparison.

After the laboratory samples were molded, they were sealed in small plastic bags. Twenty-eight days after material mixing and cylinder preparation, four cylinders were submerged in each solution in closed, 250-mL polyethylene bottles. The cylinders remained submerged, agitated by magnetic stirring, for a 28-day time period. The compressive strength of the samples was measured together with the four untreated samples. The solid-to-liquid ratio was about $50 \mathrm{~g}$ of sample to $200 \mathrm{~mL}$ of solution or 1 to 4 . The nominal sample surface area-to-volume ratio was also 1 to $4\left(50\right.$ to $\left.200 \mathrm{~cm}^{3}\right)$.

The DI solution was removed after 28 days, evaporated, and the remaining solids weighed to determine total mass lost due to the dissolution process. The amount of recovered solid was very small, so the other aqueous test solutions, because material had been added, could not be used for this purpose.

An identical set of experiments was done on the core samples collected from the BWCS Buried Test $\# 2$ beam samples (see Section 5 ). 


\subsection{Results}

The results of the laboratory test program are presented in this section. Topics include the observations made during the initial trial experiments, the relation between viscosity and slump, workability and set time results, mixture curing temperature, barrier material compressive strength and density, and the effect of possible leachates on barrier material stability.

\subsubsection{Initial Tests and Observations}

Several experiments and test were carried out initially to gain experience working with these materials in the laboratory and to determine as quickly as possible if the latex-modified Rapid Set cement would be suitable for the BWCS application.

Several experiments were performed with a variety of aggregate, latex, and water contents, both with and without set retardant. Water contents below a water-to-cement ratio (W/C) of 35 parts water to 100 parts cement (W/C of 0.35 ) were too dry to adequately mix in the laboratory. Without set retardant, these mixtures set in 3 to 5 minutes. The set time and mixing efficiency of these mixtures could be increased only by increasing the water and/or latex content to undesirable, large amounts. In general, water contents greater than $\mathrm{W} / \mathrm{C}$ of about 0.5 were found to diminish final strength and density. Water contents above W/C of about 0.5 were considered undesirable for this application because they usually have higher shrinkage and porosity, both of which tend to produce higher permeability in the final product. A mixture having a latex content of 15 parts (solids) per 100 parts cement, as recommended by the manufacturer, provided good mixing and handling properties. Latex concentrations above this value lowered the final product density and strength without significantly improving handling properties. Citric acid was tested as a set retardant, an additive to increase the workability and set time. Mixtures containing citric acid between 0.2 and 1.5 parts per 100 parts cement were evaluated. About 0.4 to 0.7 parts citric acid to 100 parts cement were found to be optimum for mixtures containing 15 parts latex (solids) and 35 to 50 parts water. Additions beyond 0.8 parts citric acid continued to retard the initial set time but did not significantly extend the time that the mixture could be easily worked.

\subsubsection{Viscosity and Slump}

Viscosity is the degree to which a liquid resists flow under an applied force. Slump is the distance the fluid cement mixture falls after a standard supporting cone (12-in. height) is removed. A thin, relatively low viscosity mixture would have a slump approaching the entire height of the cone, i.e., 10 to $11 \mathrm{in.}$. In contrast, a slump of less than, say, $1 / 2 \mathrm{in}$. would indicate a very thick and virtually unworkable mixture.

The time after component mixing that the slump is to be measured is not specified in the ASTM C-143 procedure nor in the test plan. ${ }^{6}$ However, the initial set time specification, ${ }^{6}$ in which the barrier material must be capable of supporting a 20 -psi load in 15 to 30 minutes, requires that the mixture viscosity and slump must both change rapidly with time. The slump must become zero and the viscosity must become infinitely large in no more than about 30 minutes from the time of mixture preparation. On the other hand, one of the requirements for emplacement of the barrier material is that it have a slump of 8 to $10 \mathrm{in.}$

The relationship between slump and viscosity was determined for the materials reported here and is shown in Figure 1. These data apply to barrier mixtures having 200 to 300 parts sand (ASTM C-33), 14 to 15 parts latex, and 0.4 to 0.7 parts citric acid per 100 parts cement, and having W/C of 0.35 to 0.5 . The data show that a slump of $10 \mathrm{in}$. is equivalent to a viscosity of 80,000 centipoise, and a slump of $8 \mathrm{in}$. is equivalent to a viscosity of 450,000 centipoise. The time that the mixture can be used for the BWCS application is the length of time until the slump becomes less than 8 in. or the viscosity becomes greater 


\section{Viscosity vs Slump}

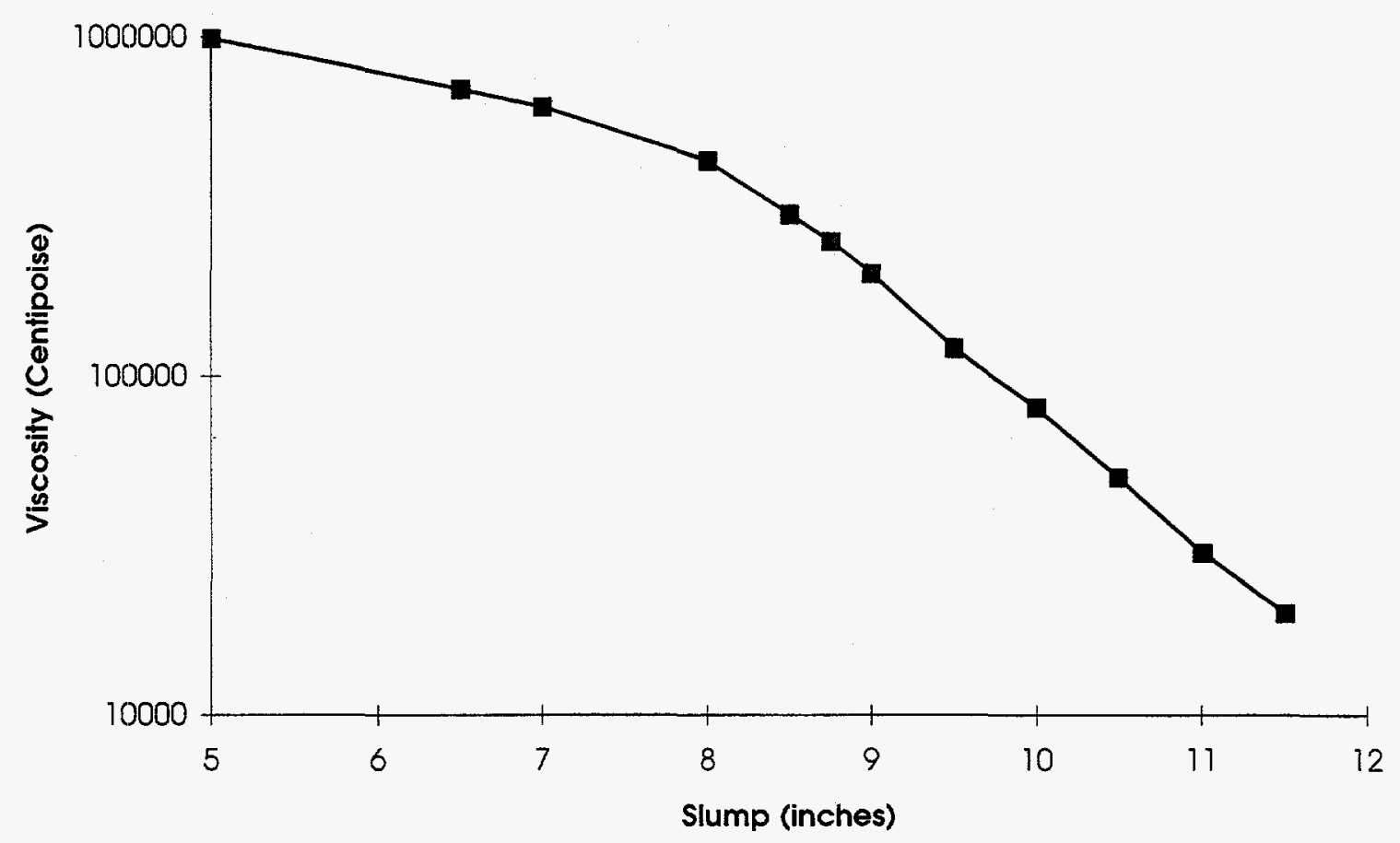

Figure 1. Viscosity versus slump.

than about 500,000 centipoise. This is the workability time in contrast to the initial set time, which is the time required for the mixture to support a 20 -psi load.

The data shown in Figure 1 also provide a very convenient means of comparing laboratory viscosity data to slump data determined in the baseline and field tests (see Section 5).

\subsubsection{Workability Time, Set Time, and Composition}

All compositions discussed here used about 15 parts latex (Modifier A, solids) to 100 parts Rapid Set cement.

Several combinations of sand to cement, as well as other components, were tested. Generally, it was found that sand-to-cement ratios greater than about 3.5 required water-to-cement ratio greater than 0.5 to maintain workability. This is illustrated in Figure 2, which shows the change in viscosity as a function of time for three sand-to-cement ratios. Figure 3 shows the change of compressive strength as a function of time for the same compositions. The data indicate that a 4-to-1 sand-cement mixture has a working time of about 9 minutes compared to the 15-minute workability time of the 2-to-1 and 3-to-1 sand-to-cement ratios. All three mixtures have reasonable set times of about 30 to 35 minutes. Note that at no point is viscosity (or slump) constant, but changes smoothly as a function of time. Similar viscosity versus time relationships are shown by the data in Figure 4 where six compositions are compared. Note that most of these compositions have water contents that are higher than recommended: 50 parts water to 100 parts cement. The higher 4-to-1 and 3.86-to-1 sand-to-cement mixtures also have relatively short workability times. All mixtures had set times greater than 30 minutes; several are greater than 40 minutes (see Figure 5). A reduction in the amount of water or citric acid would reduce both workability and set time. 


\section{Viscosity vs Time}

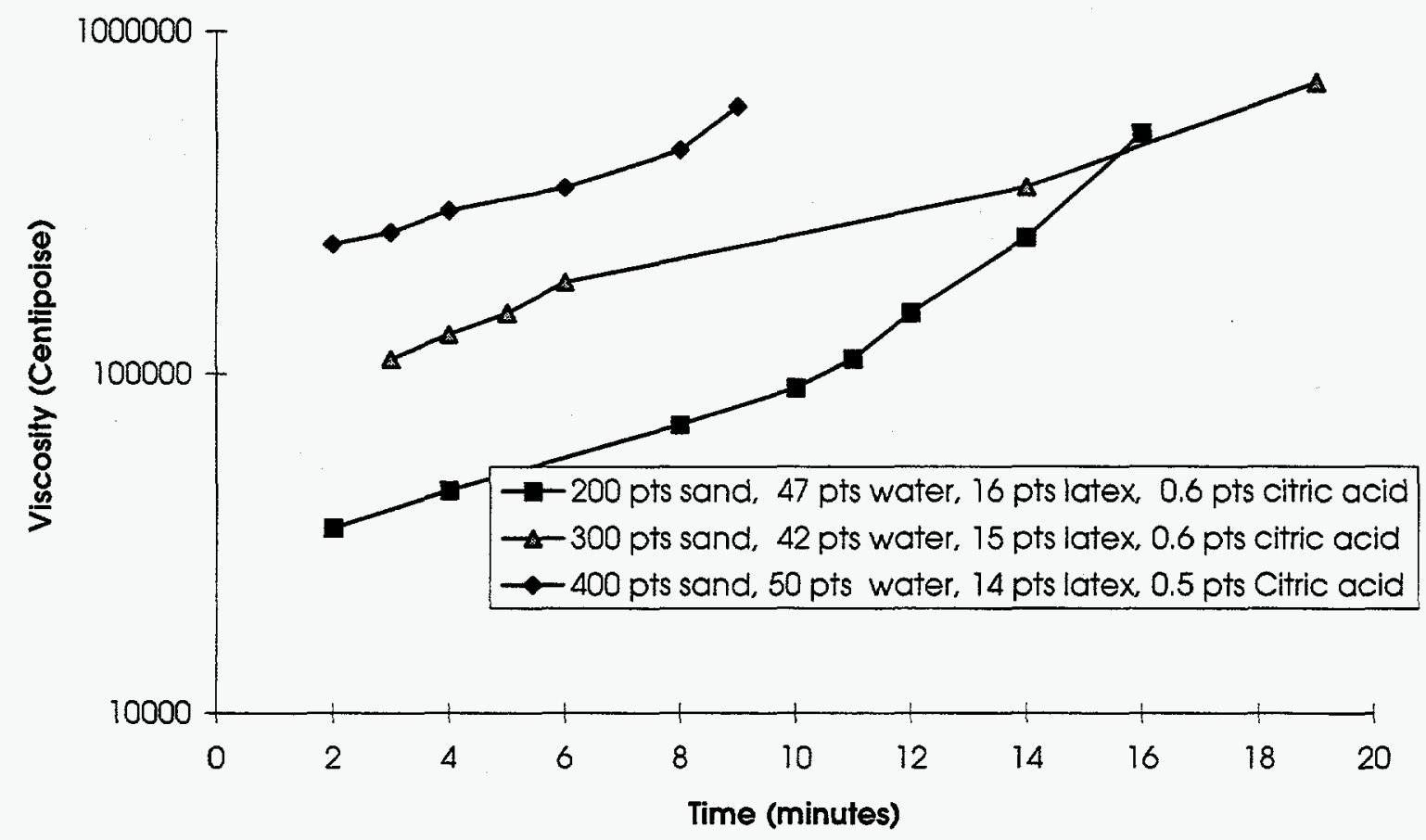

Figure 2. Viscosity versus time.

Compressive Strength vs Time

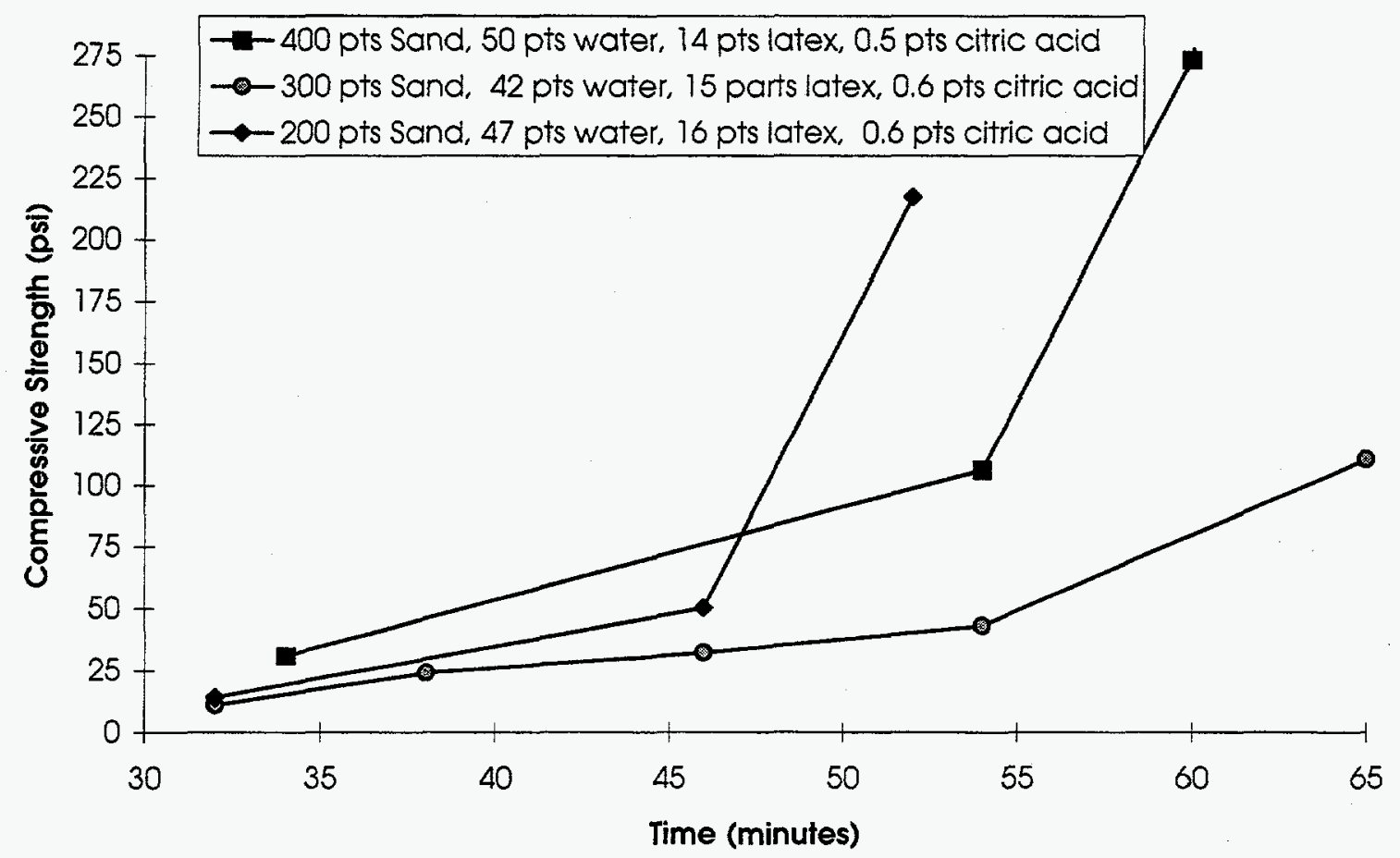

Figure 3. Compressive strength versus time. 


\section{Viscosity vs Time}

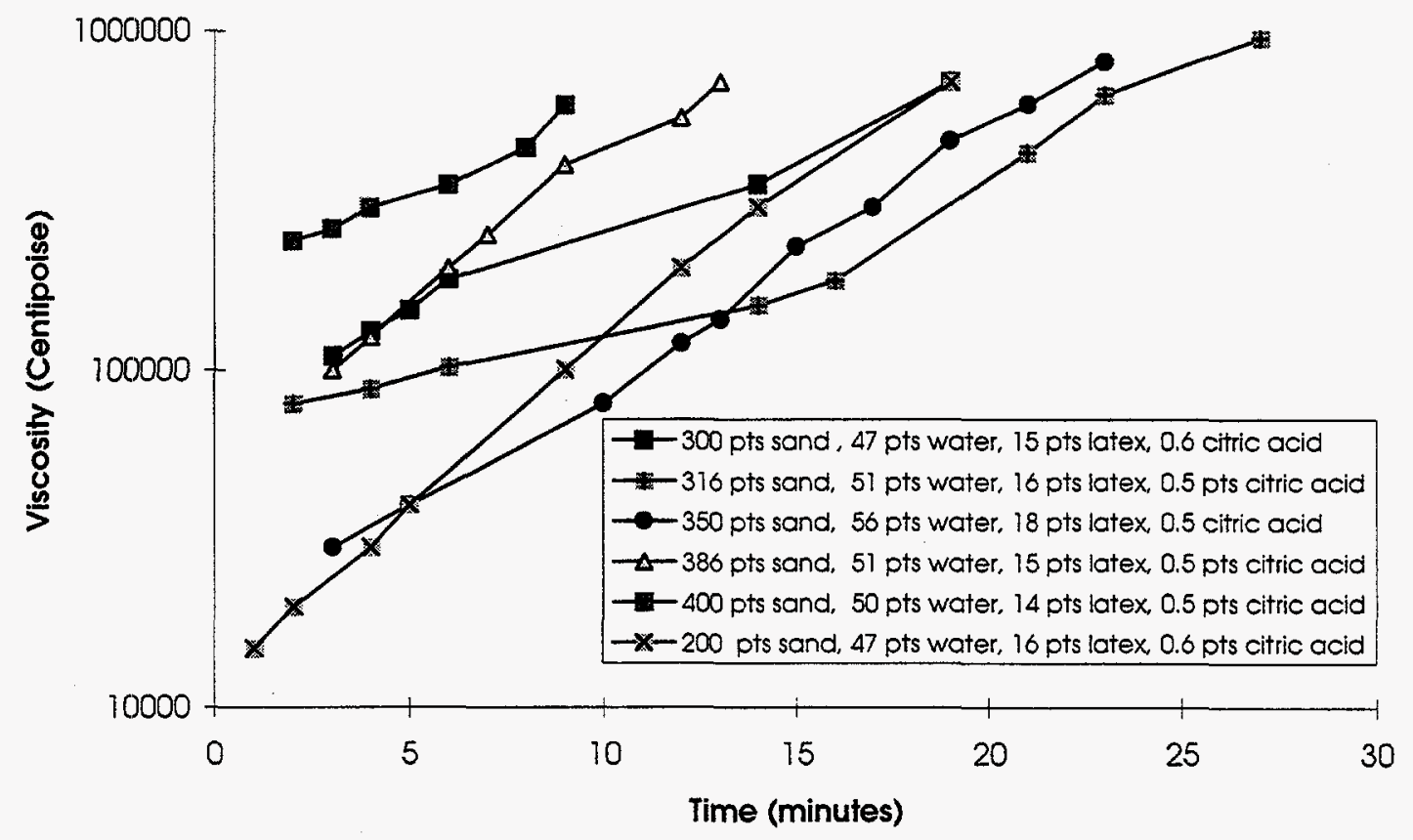

Figure 4. Viscosity versus time.

\section{Compressive Strength vs Time}

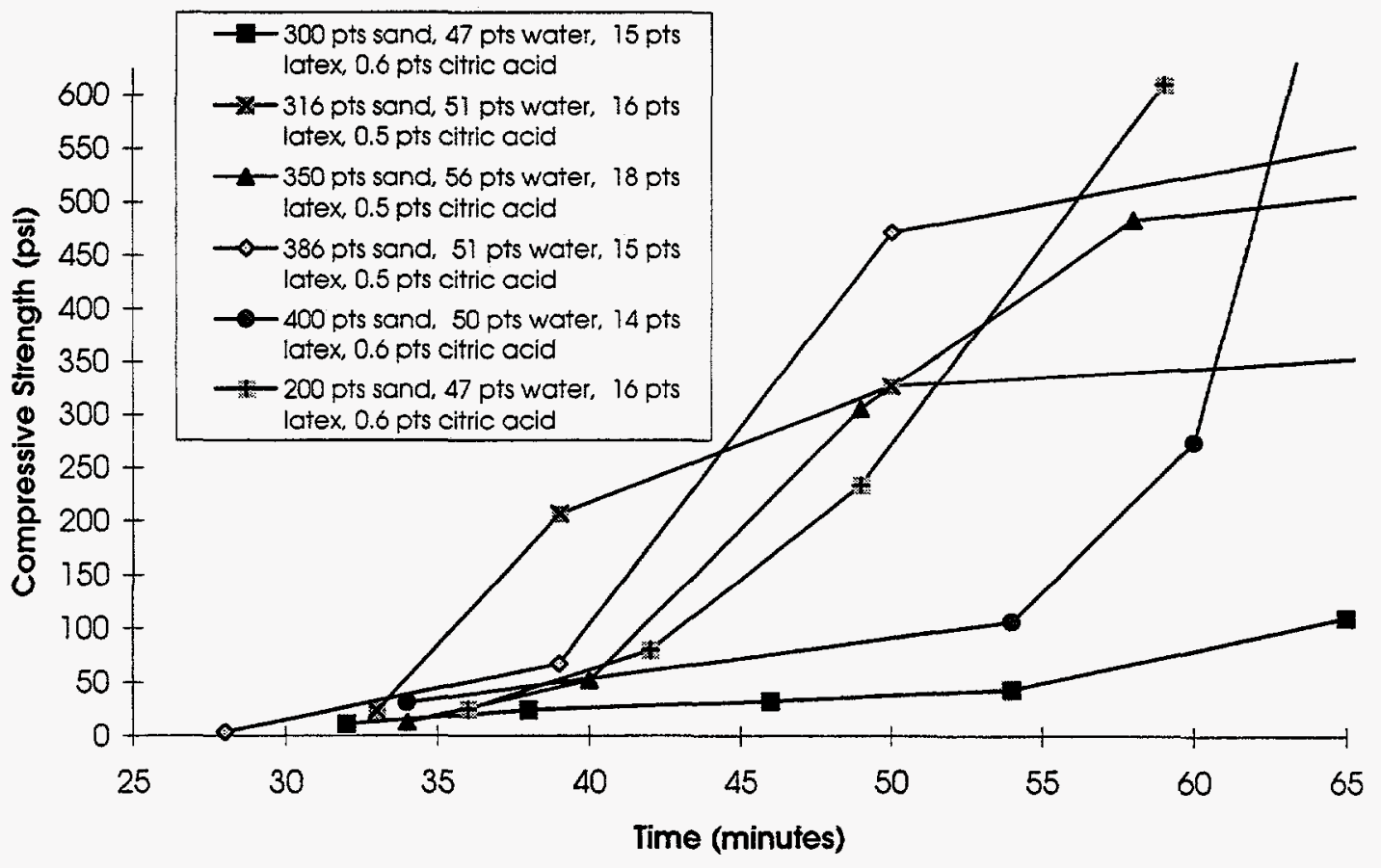

Figure 5. Compressive strength versus time. 
A very useful combination of workability and set time is illustrated by the data in Figure 6 for the composition 2 parts sand to 1 part cement, 0.47 parts citric acid to 100 parts cement, 15 parts latex to 100 parts cement, and a W/C of 0.37 . The mixture has a viscosity of 2,000 centipoise (slump about 11 in.) 2 minutes after mixing, a viscosity of 80,000 centipoise (slump about $10 \mathrm{in}$.) 13 minutes after mixing, end of workability (slump 8 in.) occurs 23 minutes after mixing, with the set time being about 32 minutes, as shown in Figure 7.

The repeatability of laboratory data are indicated by the curves in Figures 8 and 9, which show the viscosity and compressive strength data as a function of time for four batches having virtually the same composition. Generally, the precision of such laboratory data within the first 20 minutes is about \pm 5 minutes or less for a particular viscosity or compressive strength measurement. For the example given, the time to reach a viscosity of 500,000 centipoise (workability time) varies from 16 to 24 minutes and the time to reach 20 psi compressive strength (initial set time)varies from 36 to 45 minutes. Less water or citric acid in these mixtures would lower both the workability time and set time.

Initial set data curves were obtained for most laboratory batches. Examples are shown in Figures 3, 5,7 , and 9. Initial set times varied between 4 and 12 minutes for batches that had no set retardant and 20 and 90 minutes for samples with citric acid set retardant. For samples with 0.4 to 0.7 parts citric acid to 100 parts cement and W/C in the 0.35-to-0.5 range, the set times were 20 to 45 minutes.

\subsubsection{Compressive Strength and Density}

As part of the sample characterization process, compressive strength (determined at several time periods after sample preparation) and density values were measured. Compressive strength and density values for representative laboratory samples are shown in Tables 3 and 4 . These values are the mean of four measurements made 28 days after sample preparation unless otherwise indicated. The error is one sigma.

Compressive strength versus time data are shown in Figure 10 for a composition having a 2-to-1 sand-to-cement ratio, W/C of 0.4 , citric acid at 0.72 parts per 100 parts cement, and 15 parts latex (solid) per 100 parts cement. The compressive strength of this example was about 1,500 psi after 1.5 hours, 2,400 psi at 18 hours, and 3,700 psi at 28 days. The data indicate that the compressive strength would be expected to continue to increase somewhat for longer time periods. The average compressive strength of all samples having appropriate set time and workability properties was $3,500 \pm 500$ psi measured at 28 days.

Two types of density, bulk and saturated surface dry (SSD), were measured as part of the laboratory work. Bulk density is that of the 'as made' concrete, air or oven dried, and was determined on all samples. SSD is the density of the sample with a dry exterior but with internal pores that are watersaturated. Bulk density values ranged from 1.9 to $2.2 \mathrm{~g} / \mathrm{cm}^{3}$, generally about $2 \mathrm{~g} / \mathrm{cm}^{3}$, and usually decreased slightly with an increased water-to-cement ratio.

\subsubsection{Temperature}

All cement-based materials evolve heat as they hydrate (set). This usually results in a temperature increase in the cementatious material during the set and cure processes. A requirement specified in the test $\operatorname{plan}^{6}$ is that the material not reach or exceed $100^{\circ} \mathrm{C}$. This specification was a safety requirement and was included in order to avoid the possibility of steam explosions during the testing of a new application of a very fast reacting exothermic material. As measured in a $3 \times 6$-in. test cylinder, the maximum temperature increase observed was $55^{\circ} \mathrm{C}$ at about 100 minutes after mixing. The batch composition was 200 parts sand, 44 parts water, 15 parts latex (solids), and 0.7 parts citric acid to 100 parts cement (by weight). The data are shown in Figure 11. Temperature was measured at the center of the cylinder. 
Viscosity vs Time

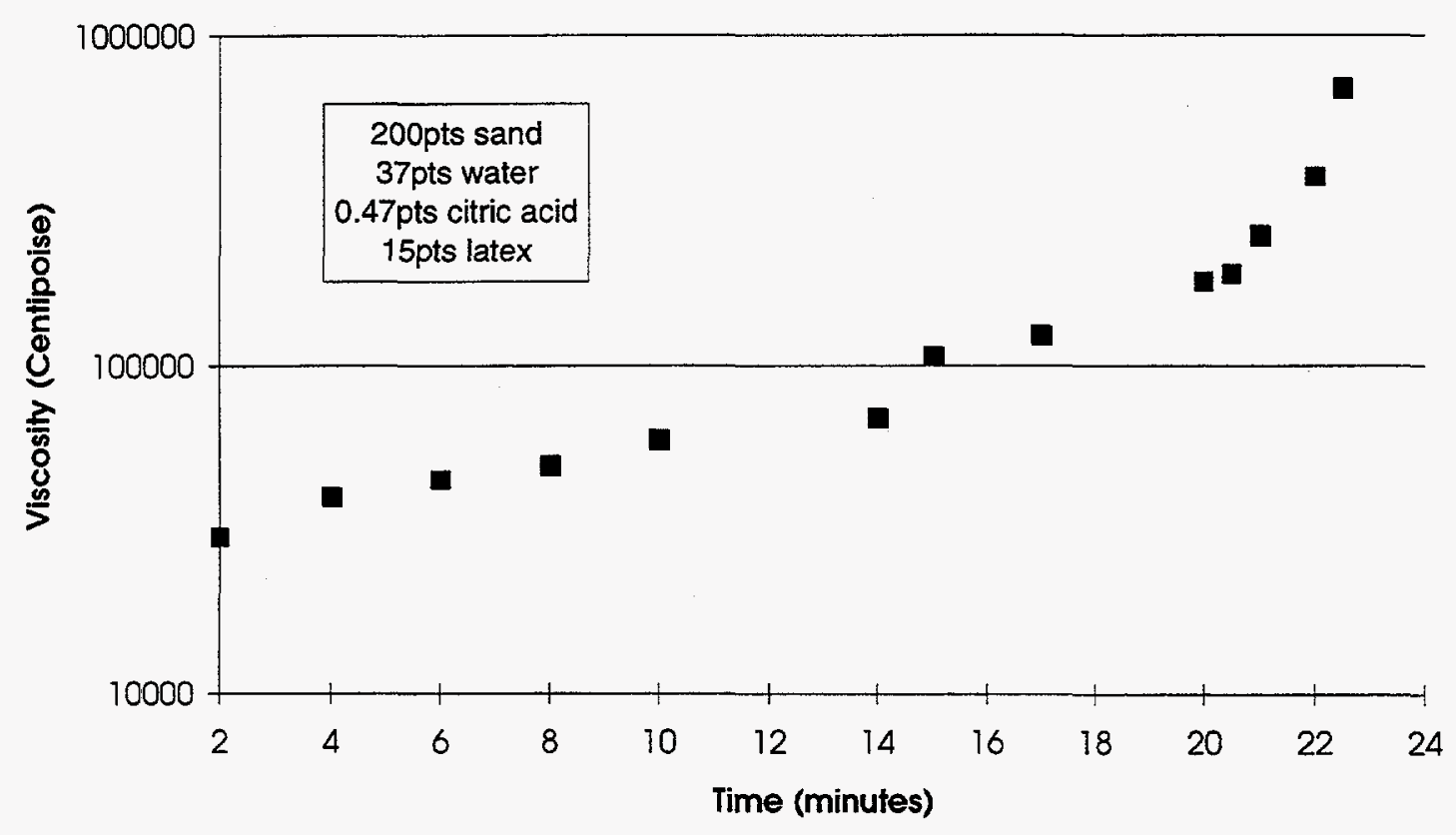

Figure 6. Viscosity versus time.

\section{Compressive Strenght vs Time}

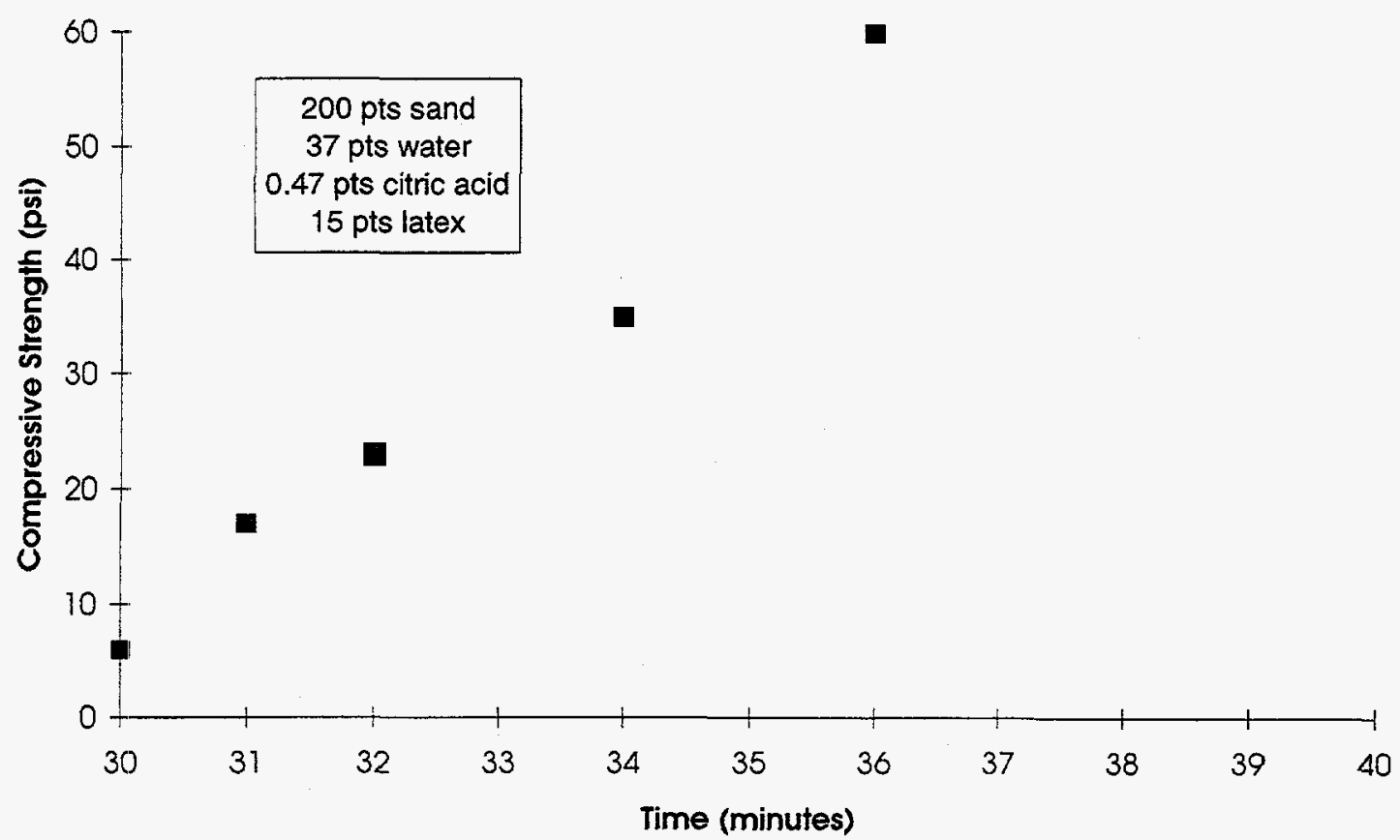

Figure 7. Compressive strength versus time. 


\section{Viscosity vs Time \\ 200 pts Sand 100pts Cement}

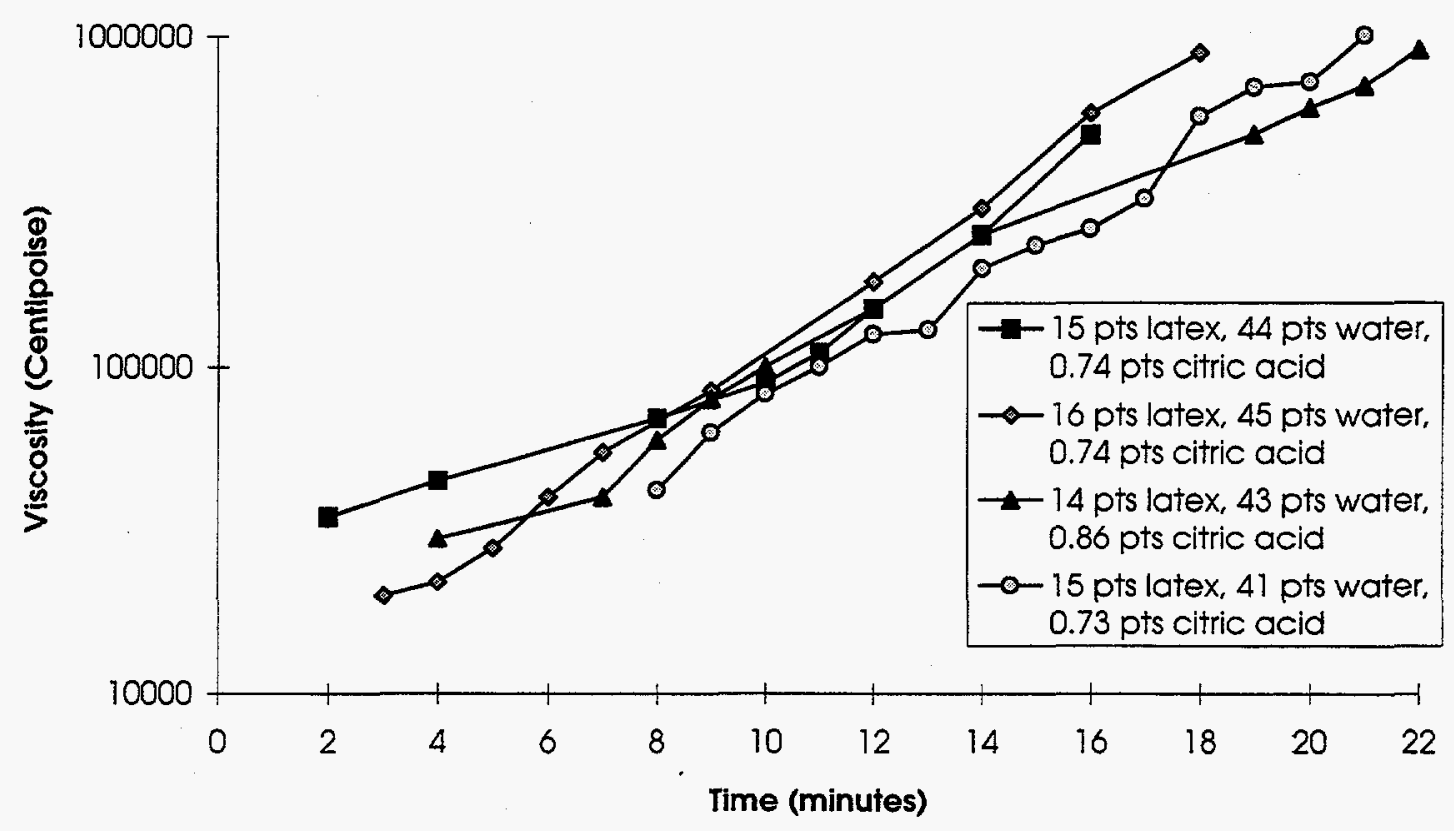

Figure 8. Viscosity versus time (200 parts sand and 100 parts cement).

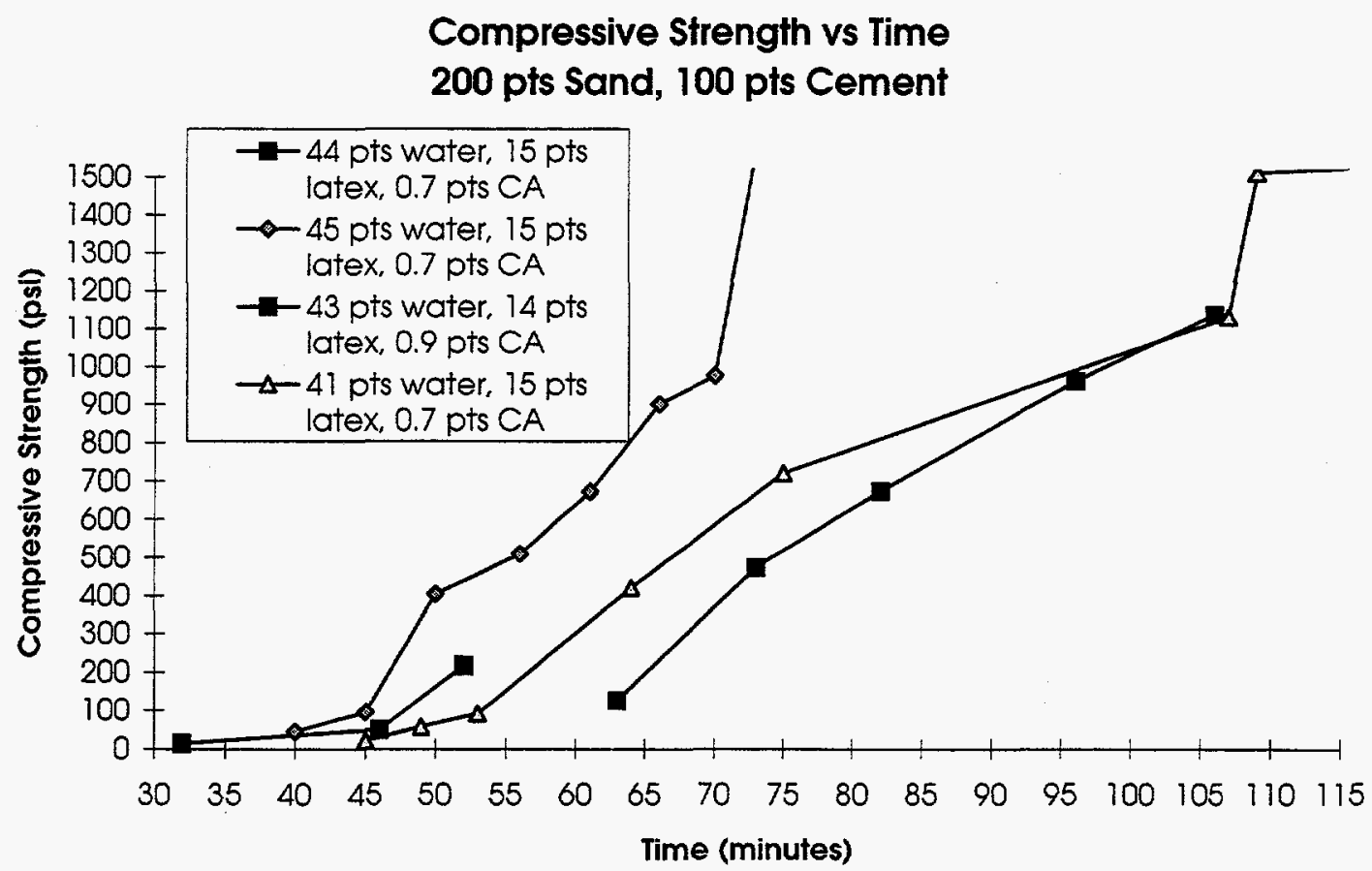

Figure 9. Compressive strength versus time (200 parts sand and 100 parts cement). 
Table 3. Composition and physical characteristics of the 2-to-1 sand-to-cement mixtures.

\begin{tabular}{|c|c|c|c|c|c|c|c|}
\hline $\begin{array}{c}\text { Total } \\
\text { Water }^{\mathrm{a}}\end{array}$ & $\begin{array}{l}\text { Latex } \\
\text { Solids }^{\mathrm{a}} \\
\end{array}$ & $\begin{array}{l}\text { Citric } \\
\text { Acid }^{\mathrm{a}}\end{array}$ & $\begin{array}{c}\text { Workable } \\
\text { (Min) }\end{array}$ & $\begin{array}{l}\text { Initial Set } \\
\text { (Min) }\end{array}$ & $\begin{array}{l}\text { Average } \\
\text { Compressive } \\
\text { Strength }^{\mathrm{b}} \\
\text { (psi) }\end{array}$ & $\begin{array}{c}\text { Average } \\
\text { Density } \\
\mathrm{SSD}^{\mathrm{c}} \\
\left(\mathrm{g} / \mathrm{cm}^{3}\right)\end{array}$ & $\begin{array}{c}\text { Average } \\
\text { Density }^{b} \\
\text { Bulk } \\
\left(\mathrm{g} / \mathrm{cm}^{3}\right)\end{array}$ \\
\hline 41 & 15 & 0.7 & 17 & 45 & $3,020 \pm 451$ & $2.11 \pm 0.06$ & $1.96 \pm 0.02$ \\
\hline 43 & 14 & 0.9 & 19 & 44 & $2,930 \pm 590$ & $2.18 \pm 0.08$ & $1.97 \pm 0.04$ \\
\hline 45 & 15 & 0.7 & 16 & 36 & $3,830 \pm 490$ & $2.08 \pm 0.04$ & $2.03 \pm 0.03$ \\
\hline 44 & 15 & 0.7 & 15 & 40 & $3,570 \pm 310$ & $2.11 \pm 0.01$ & $2.04 \pm 0.01$ \\
\hline 49 & 14.5 & 0.6 & 17 & 34 & $3,730 \pm 1,300^{d}$ & $2.10 \pm 0.02$ & $2.02 \pm 0.02$ \\
\hline $\begin{array}{l}\text { b. Mea } \\
\text { c. Surf } \\
\text { d. Ave }\end{array}$ & rated & ths & Ind deviati & er $25 \%$. & & & \\
\hline
\end{tabular}

Table 4. Composition and physical characteristics of several sand-to-cement ratios.

\begin{tabular}{|c|c|c|c|c|c|c|c|c|}
\hline $\begin{array}{l}\text { Sand to } \\
\text { Cement }^{a}\end{array}$ & $\begin{array}{l}\text { Water to } \\
\text { Cement }^{\circ}\end{array}$ & $\begin{array}{l}\text { Latex } \\
\text { Solids }^{c}\end{array}$ & $\begin{array}{l}\text { Citric } \\
\text { Acid }\end{array}$ & $\begin{array}{l}\text { Workable } \\
\text { (Min) }\end{array}$ & $\begin{array}{l}\text { Initial } \\
\text { Set }^{e} \\
(\mathrm{Min})\end{array}$ & $\begin{array}{l}\text { Compressive } \\
\text { Strength } \\
\text { (psi) }\end{array}$ & $\begin{array}{c}\text { Density } \\
\mathrm{SSD} \\
\left(\mathrm{g} / \mathrm{cm}^{3}\right)\end{array}$ & $\begin{array}{l}\text { Density } \\
\text { Bulk } \\
\left(\mathrm{g} / \mathrm{cm}^{3}\right)\end{array}$ \\
\hline 4 & 0.50 & 14.5 & 0.50 & 9 & 45 & $3,300 \pm 280$ & $2.1 \pm 0.003$ & $2.07 \pm 0.04$ \\
\hline 3.86 & 0.51 & 15.3 & 0.51 & 13 & 44 & $3,380 \pm 690$ & $2.06 \pm 0.12$ & $2.03 \pm 0.14$ \\
\hline 3.5 & 0.56 & 18 & 0.55 & 21 & 43 & $3,460 \pm 450$ & $2.20 \pm 0.07$ & $2.06 \pm 0.02$ \\
\hline 3.16 & 0.51 & 15.8 & 0.51 & 24 & 36 & $3,880 \pm 120$ & $2.09 \pm 0.03$ & $2.08 \pm 0.01$ \\
\hline 3 & 0.47 & 14.8 & 0.62 & 18 & 40 & $3,970 \pm 1,040^{f}$ & $2.18 \pm 0.01$ & $2.05 \pm 0.02$ \\
\hline 2 & 0.47 & 14.5 & 0.62 & 17 & 34 & $3,730 \pm 1,300^{\mathrm{f}}$ & $2.10 \pm 0.02$ & $2.02 \pm 0.02$ \\
\hline $\begin{array}{l}\text { a. ASTM-3 } \\
\text { b. Rapid Se } \\
\text { c. DOW M } \\
\text { d. The time } \\
\text { e. The time } \\
\text { f. Average }\end{array}$ & $\begin{array}{l}\text { Ind. } \\
\text { ment. } \\
\text { ier A latex } \\
\text { cosity rem } \\
\text { il compres } \\
\text { wo samples }\end{array}$ & $\begin{array}{l}\text { d unde } \\
\text { streng } \\
\text { e stand }\end{array}$ & $\begin{array}{l}000 \\
\text { eede }\end{array}$ & $\begin{array}{l}\text { oise. } \\
\text { si. } \\
\text { over } 25 \% \text {. }\end{array}$ & & & & \\
\hline
\end{tabular}


Compressive Strength vs Time

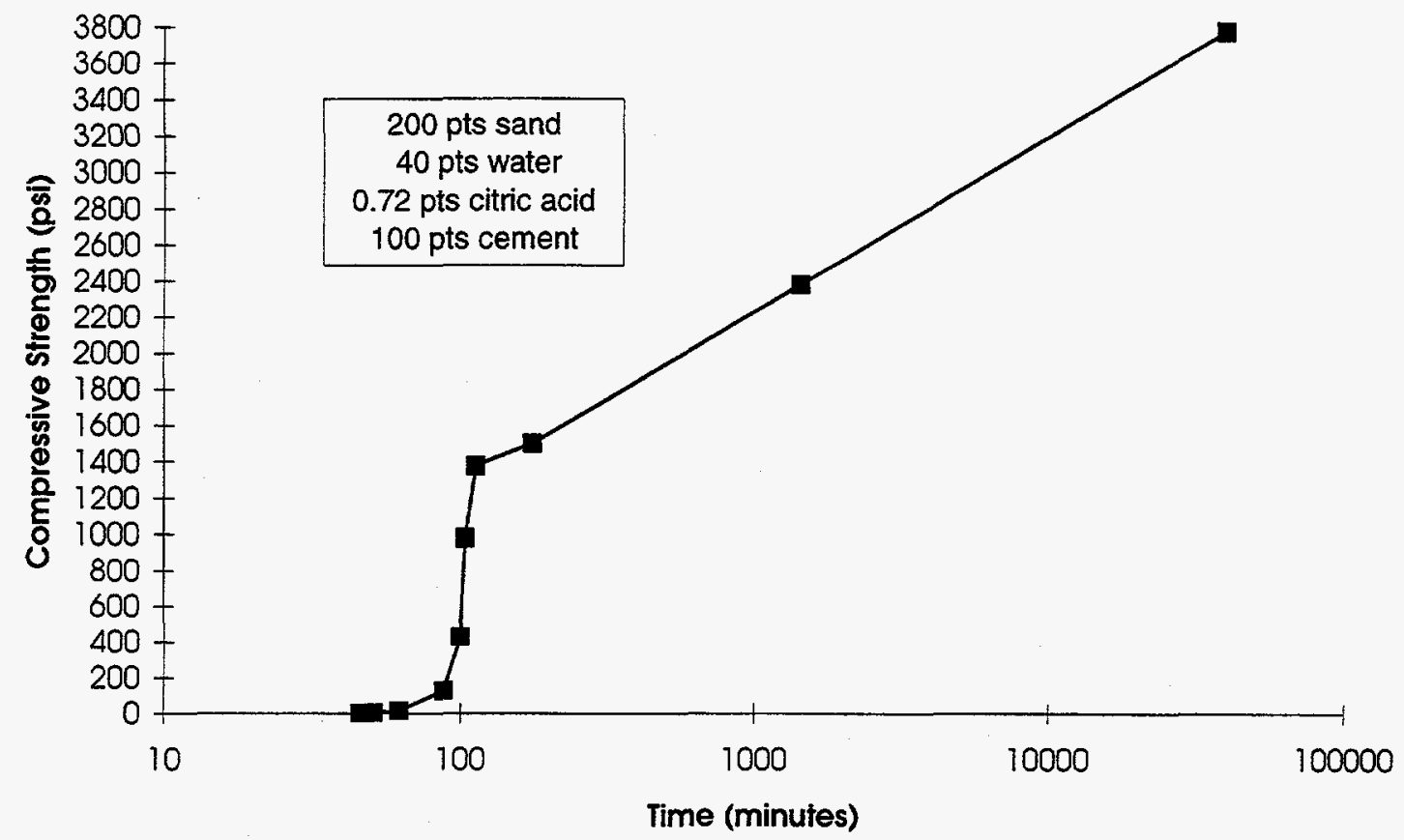

Figure 10. Compressive strength versus time.

\section{Temperatures vs Time \\ 3" $\times 6$ " Monolith}

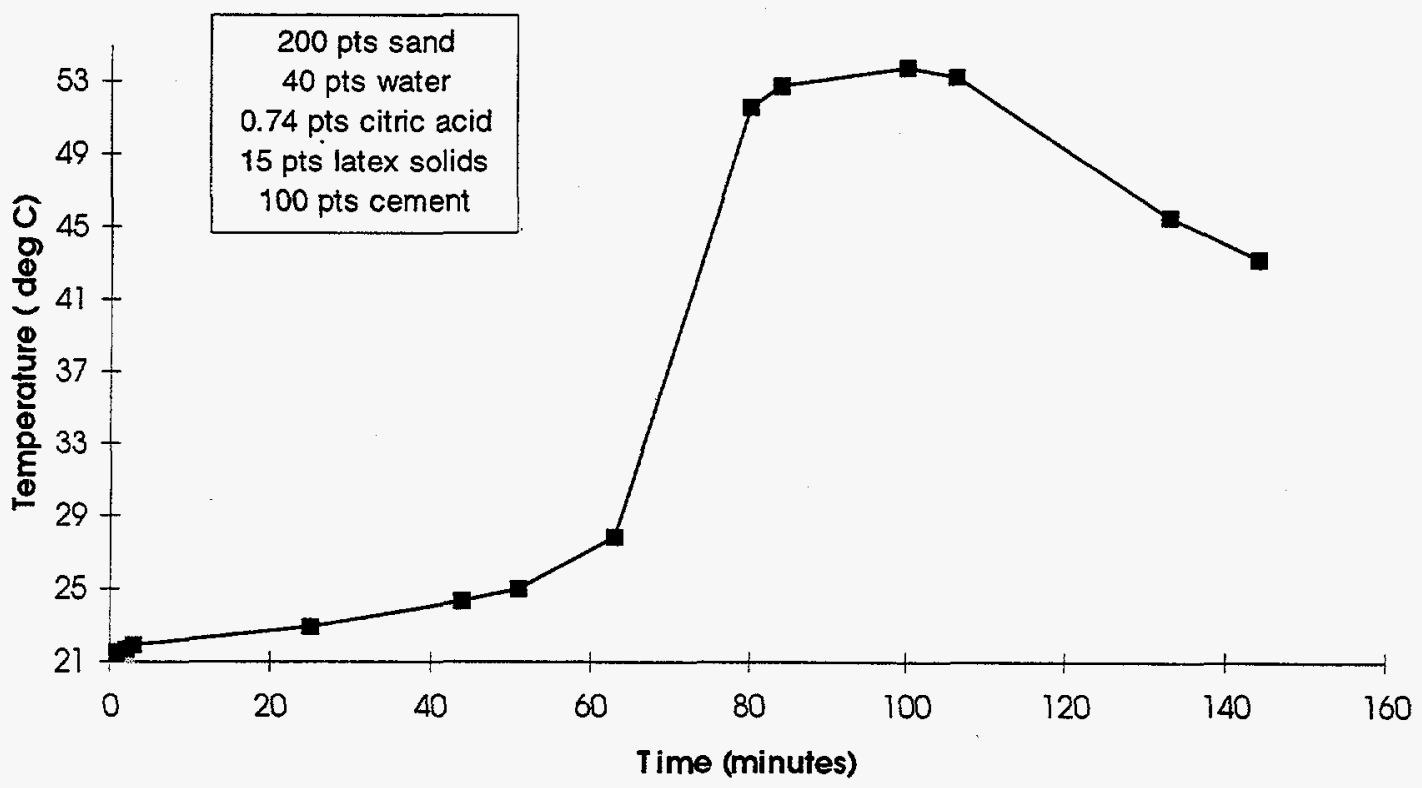

Figure 11. Temperature versus time. 
In comparison, $6 \times 12$-in. cylinders of an ordinary, general purpose Portland cement ASTM type I mixture increased in temperature from room temperature to $44^{\circ} \mathrm{C}$ in about 2 hours. ${ }^{7}$ As expected, the barrier materials show a sharp temperature rise during the curing process. They do not appear to pose a safety problem as a possible steam explosion source.

\subsubsection{Aqueous Treatment and Material Stability}

The barrier material will be applied to a waste site in an arid environment and should have chemical properties that are compatible with the soil and groundwater typical of arid climates. In such an environment, the barrier material is expected to be in the vadose zone and not in the water-saturated region below the water table. However, it is virtually certain that the barrier material will be in at least intermittent contact with aqueous solutions saturated with the mineral calcite and probably gypsum also. Gypsum can be especially troublesome for certain cementatious materials because the sulfate can react with the cement, causing cracking. Such behavior is very undesirable in a barrier material intended to have low permeability and to block the movement of contaminant materials. On the other hand, groundwaters in arid regions are typically alkaline, $\mathrm{pH}$ about 9 , which greatly decreases the rate of cement degradation compared to, for example, more acid groundwaters of the eastern United States. The following is an account of experiments to assess the affect of carbonate, sulfate, and RAHCO International test site ${ }^{8}$ soil leachates on the latex-modified Rapid Set cement.

Laboratory-prepared $1 \times 2$-in. molded samples and similar $1.25 \times 2.5$-in. cylinders core-drilled from the BWCS buried Test Run \#2 material were treated to three types of aqueous solutions for 28 days: distilled-deionized water, water saturated with calcite and gypsum, and water saturated with the minerals in the soil from the RAHCO International test site in Spokane, Washington. The data indicate that there is no significant difference in compressive strength among the treated samples. The compressive strength of the control sample treated with distilled water is identical to the compressive strength of the carbonate -sulfate-treated sample as well as the soil-leachate-treated sample. The data do not indicate that any reactions involving carbonate, sulfate, or soil leachate occurred. However, all treated samples show significantly less compressive strength than samples that were not treated in the solutions, about 2,300 psi versus 3,600 psi for the laboratory-molded samples and 2,450 psi versus 4,225 psi for the field core samples. This suggests that all the treated samples are interacting with the water in the solutions. The high standard deviation of the compressive strength measurements suggests nonuniform loss of sample integrity. These data are shown in Table 5.

The $\mathrm{pH}$ of the solutions was monitored over the 28 -day period. Solution $\mathrm{pH}$ was between 10.8 and 11.8 , values typical of solutions in contact with cementatious material. Steady-state conditions were usually reached in about 2 to 6 days.

The dry residue from the distilled water leachate indicated that $1.1 \mathrm{wt} \%$ was lost from the laboratorymolded test cylinders. This number includes both inorganic material and organic material from the latex.

Examination, using a binocular microscope, of the samples broken during the compressive strength tests showed that unidentified accicular structures, having an aspect ratio of at least 50 to 1 , lined the inner surface of bubble-like open spaces, probably air bubbles, within the matrix of all of the treated samples. The long axis of the features, presumed to be crystals, was perpendicular to the interior surface of the bubble. Similar open spaces were present in the untreated control samples, but no accicular crystals or other unusual features were observed. Similar conditions were observed in the field test core samples. No evidence of cracking, spalling, swelling, or other features suggesting change due to the solution was observed. 
Table 5. Results of aqueous treatment of laboratory-molded and field core cylinders.

\begin{tabular}{lcc} 
& \multicolumn{3}{c}{$\begin{array}{c}\text { Compressive Strength } \\
(\mathrm{psi})\end{array}$} \\
\cline { 2 - 3 } Leachate & Laboratory-Molded Samples & Field Core Samples \\
\hline 1 & $2,360 \pm 640$ & $3,043 \pm 608$ \\
2 & $2,210 \pm 270$ & $2,238 \pm 320$ \\
3 & $2,490 \pm 730$ & $2,070 \pm 220$ \\
4 & $3,670 \pm 220$ & $4,225 \pm 295$ \\
& & \\
1. $\mathrm{CaCO}_{3}, \mathrm{CaSO}_{4}-2 \mathrm{H}_{2} \mathrm{O}$ saturated leachate. & \\
2. Soil-saturated leachate. & & \\
3. Distilled water leachate. \\
4. Unleached samples for comparison.
\end{tabular}

The decrease in compressive strength is normal for latex-modified mortar ${ }^{5}$ and may be beneficial for the BWCS application provided that other properties are not degraded. Typically, water immersion causes swelling of the latex and a decrease in permeability of the barrier material as well as a loss of some compressive strength. ${ }^{5}$ The interaction stops at some point and is reversible if the water is removed in some manner. The decrease in compressive strength may indicate an increase in the ability of the material to deform without fracture, i.e., the material becomes less brittle and less likely to crack.

\subsection{Summary}

The data indicate that the optimum BWCS barrier material compositions would be: 100 parts Rapid Set cement, 35 to 50 parts water, 15 parts latex solids (Modifier A), 200 to 300 parts concrete sand ASTM C-33, and 0.4 to 0.7 parts citric acid.

The temperature maximum of $54^{\circ} \mathrm{C}$ during curing suggests that the rate of heat release by Rapid Set cement is not sufficient to cause a safety issue in the field, namely a steam explosion.

The treatment of cured laboratory samples and field core samples in several aqueous solutions indicated that water decreased the compressive strength of the treated samples in a manner typical of latex-modified cement by $30 \%$ to $50 \%$, accompanied by a $1 \%$ weight loss in sample mass and a slight decrease in density. Calcite and gypsum saturated solutions, as well as leachate from the test site soils, had no apparent effect on the barrier material other than the effect of water. 


\section{FIELD OBSERVATIONS AND SPECIMEN COLLECTION}

During the period of May 29 and 30, 1997, RAHCO International completed the buried barrier emplacement portion of the Barrier POP Test at its facility in Spokane, Washington ${ }^{8}$ by casting a horizontal barrier beneath a 4-in. layer of local soil. The final slab was made up of three test runs. ${ }^{8}$ Test Run \#1 was carried out May 29 while Test Runs \#2 and \#3 were completed May 30. Two stop-start joints were produced. The first, for an overnight time period, was formed between Test Runs \#1 and \#2, and the second was produced by a stop of 1.5 hours between Test Runs \#2 and \#3.

Prior to the buried portion of the POP tests, RAHCO International performed a set of visual tests, ${ }^{8}$ which included validation of the barrier material and modifications to the initial formulation to optimize the material for field application.

After the POP test, the slab was covered with local soil to a depth of about $2 \mathrm{ft}$ followed by plastic sheeting. During June 24 and 25, 1997, the slab was excavated, the air permeability of the barrier containing the overnight joint was measured (see Section 4), and core and beam samples were collected for laboratory characterization (see Section 3.2).

\subsection{Material Production and Composition}

A concrete continuous mixer truck and a concrete pump truck were used during the field test to produce and pump the barrier materials. ${ }^{8}$ The continuous mixer mechanically proportioned and mixed the barrier materials, providing a steady flow of materials into the concrete pump. The mixer has a 100- $\mathrm{ft}^{3}$ cement bin, two aggregate bins, a 320-gal water tank, and a 320-gal latex tank. The aggregate and cement were continuously metered onto a conveyor belt and sprayed with aqueous citric acid solution ( $50 \mathrm{wt} \%$ acid). This mixture was discharged into a hopper where the latex and water were added. An auger blended the mixture and drove the material out the discharge chute into the concrete pump hopper. The concrete pump then discharged the barrier material into the distribution system. The mixing time generally ranged from about 20 seconds to 1 minute. The proportions of mixture components changed during the pour. The proportions at the start and finish of the pour are given in Table 6.

Table 6. Mix proportions for Test Run \#2.

\begin{tabular}{|c|c|c|c|}
\hline Component & Start & wt\% & Parts per 100 Parts Cement \\
\hline Rapid Set cement & $88 \mathrm{lb}$ & 24 & 100 \\
\hline Cement sand (ASTM C33) & $230 \mathrm{lb}$ & 63 & 260 \\
\hline Latex (solids) ${ }^{\mathrm{a}}$ & $13.4 \mathrm{lb}$ & 3.7 & 15.2 \\
\hline Water (total) & $34.5 \mathrm{lb}$ & 9.4 & 39 \\
\hline Citric acid & $0.35 \mathrm{lb}$ & 0.1 & 0.43 \\
\hline Component & Finish & $\mathrm{wt} \%$ & Parts per 100 Parts Cement \\
\hline Rapid Set cement & $88 \mathrm{lb}$ & 23 & 100 \\
\hline Cement sand (ASTM C33) & $257 \mathrm{lb}$ & 66 & 290 \\
\hline Latex (solids) ${ }^{a}$ & $13.8 \mathrm{lb}$ & 3.6 & 15.7 \\
\hline Water (total) & $29.1 \mathrm{lb}$ & 7.5 & 33 \\
\hline Citric acid & $0.35 \mathrm{lb}$ & 0.09 & 0.43 \\
\hline
\end{tabular}

a. Latex was Modifier A, manufactured by the Dow Chemical Company. 


\subsection{Slab Excavation and Field Observation}

The soil covering the slab was about $2 \mathrm{ft}$ thick and was very carefully removed using a front loader. Final cleanup was done by hand using a shovel followed by a broom. It was noted that the covering soil was moist to the touch and the top of the slab was wet when the soil was removed.

Careful examination indicated that the slab contained a hairline crack in the Test Run \#2 material, the only defect identified by field observations. The hairline crack was located parallel to and 40 in. from the left side of the slab as viewed looking in the direction of header movement (Figure 12) and is also shown in the core hole in Figure 13. The hairline crack terminated against the material of Test Run \#1 and also Test Run \#3. It does not pass beyond the boundaries of Test Run \#2. A core drilled through the slab showed that the hairline crack was vertical in the slab (Figures 14 and 15).

As measured in the field, the first run produced a segment $27 \mathrm{in.} \mathrm{wide.} \mathrm{The} \mathrm{second} \mathrm{run} \mathrm{produced} \mathrm{a}$ segment $37 \mathrm{in}$. wide, and the final run produced a segment $12 \mathrm{in}$. wide. The side-to-side dimensions of the slab were 120 in., and the thickness ranged from 12 to 14 in.

\subsubsection{Sample Collection}

All measurements and sample collections were made from the material of Test Run \#2 because this run contained the overnight stop-start joint and sufficient material for the samples required for laboratory measurements. Two 3.0-in. diameter bore holes were drilled, the air permeability measuring cells were installed, and the air permeability was measured (see Section 4.1 ). Then, 15 drill core samples 2.75 in. in diameter (with a 3.0-in. diameter hole) were taken using a water-cooled diamond drill. Four of these were used to assess barrier mixture component separation and segregation (see Section 5.1) and were systematically located in the corners of Test Run \#2 material. For the petrographic analysis, a core was taken from each corner of the Test Run \#2 material, $1 \mathrm{ft}$ from the slab side and $8 \mathrm{in}$. from the start-stop joints. To an observer looking in the direction of header movement, ${ }^{8}$ Core $\# 3$ was located on the left next to the overnight stop-start joint with Test Run \#1, Core \#6 was located on the left next to stop-start joint ( 1.5 hours between runs) with Test Run \#3. Core \#15 was located on the right next to stop- start joint with Test Run \#1, Core \#17 was located on the right next to stop-start joint with Test Run \#3. Ten cores were drilled through the slab on a circular pattern $2 \mathrm{ft}$ in diameter and that also included Cores \#3 and \#6. The remaining core (\#16) was drilled on the fracture, 8 in. from the start-stop joint with Test Run \#3. After the core samples had been taken, four $6 \times 6 \times 24$-in. beams were cut from the right side of the slab using water-cooled diamond saws. Finally, because the results of the air permeability test indicated imperfect sealing of the apparatus to the barrier material, a $14 \times 14 \times 36$-in. block containing the air permeability bore holes and cells was cut from the slab using water-cooled diamond saws, mounted on a pallet, and shipped to the INEEL MTL.

\subsubsection{Summary Field Observations}

The field observations showed that the slab was visibly wet at the time of excavation, suggesting that the water content of the overlying soil was near or at water saturation during the curing period of the barrier material.

A single hairline crack was found in the buried test slab. The hairline crack is located in the material of Test Run \#2 and is parallel to the sides of the slab. The hairline crack is vertical and passes completely through the Test Run \#2 material, but does not pass into either the material of Test Run \#1 or Test Run \#3. In contrast, no cracks were observed in the virtually identical slabs produced during the visual tests. ${ }^{8}$ Possible reasons for the differential shrinkage are unknown at this time. 


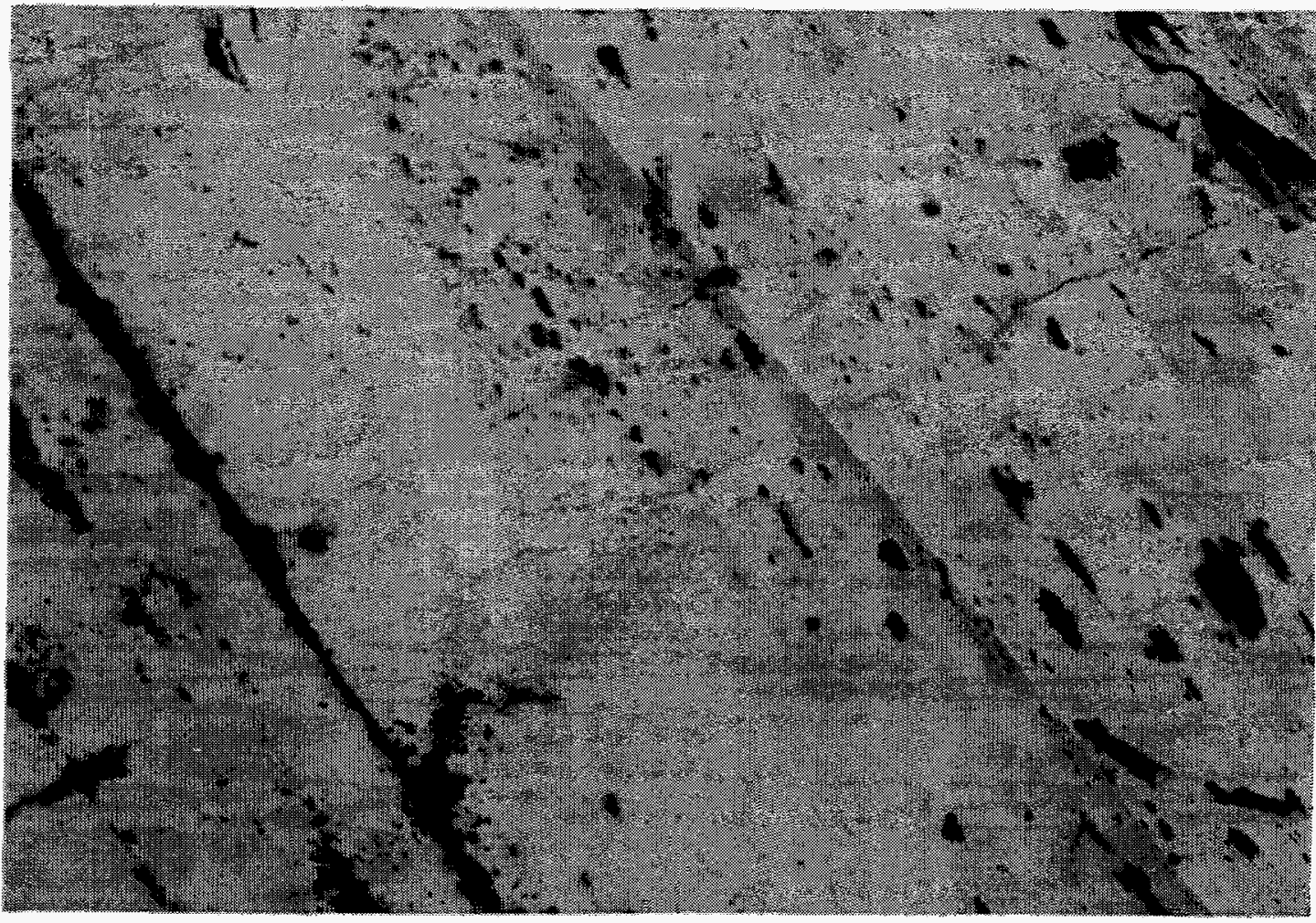

Figure 12. Hairline fracture in BWCS Test Run \#2. Fracture highlighted with water for greater visibility.

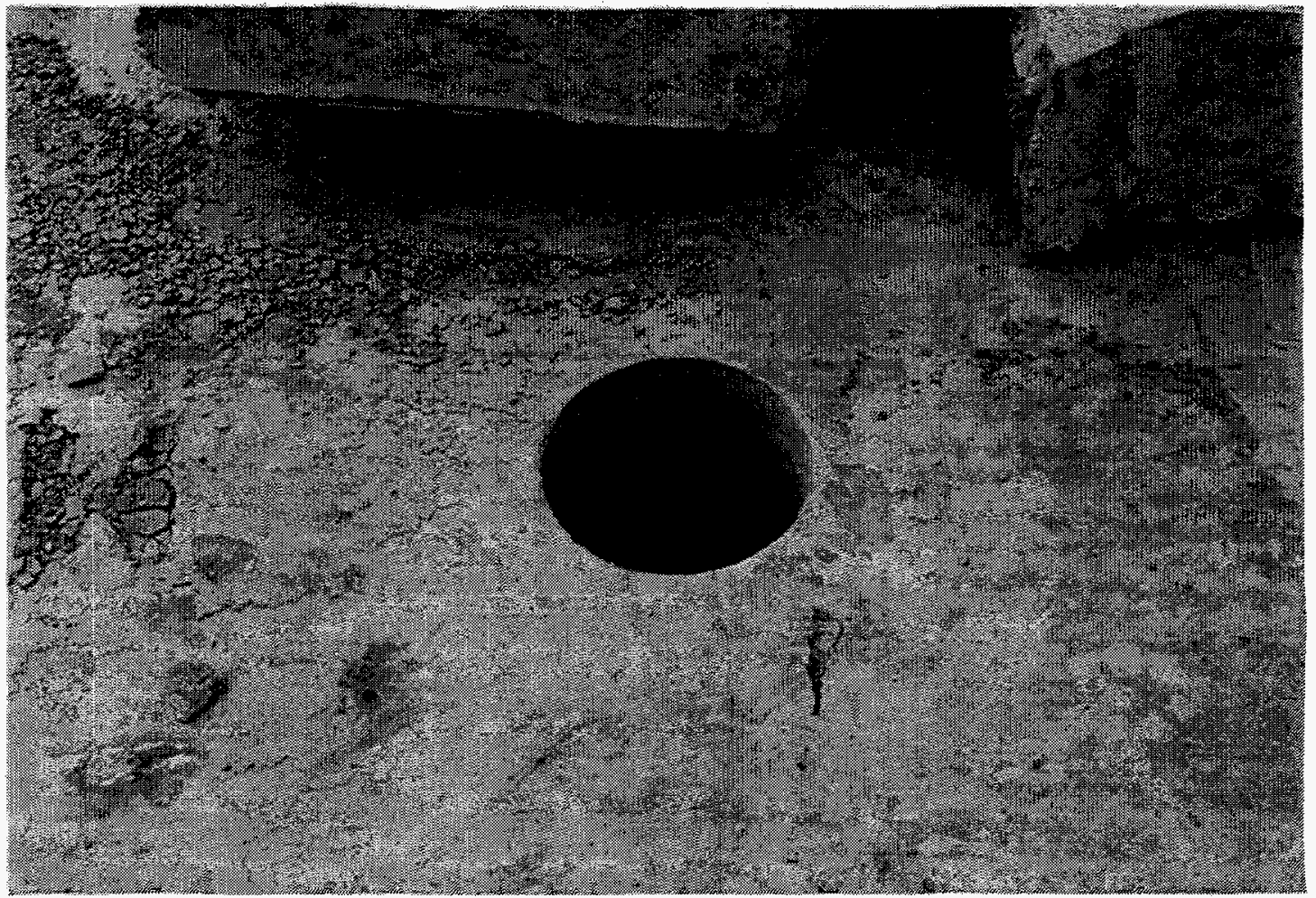

Figure 13. Core hole across the hairline fracture. Fracture highlighted with water for greater visibility. 


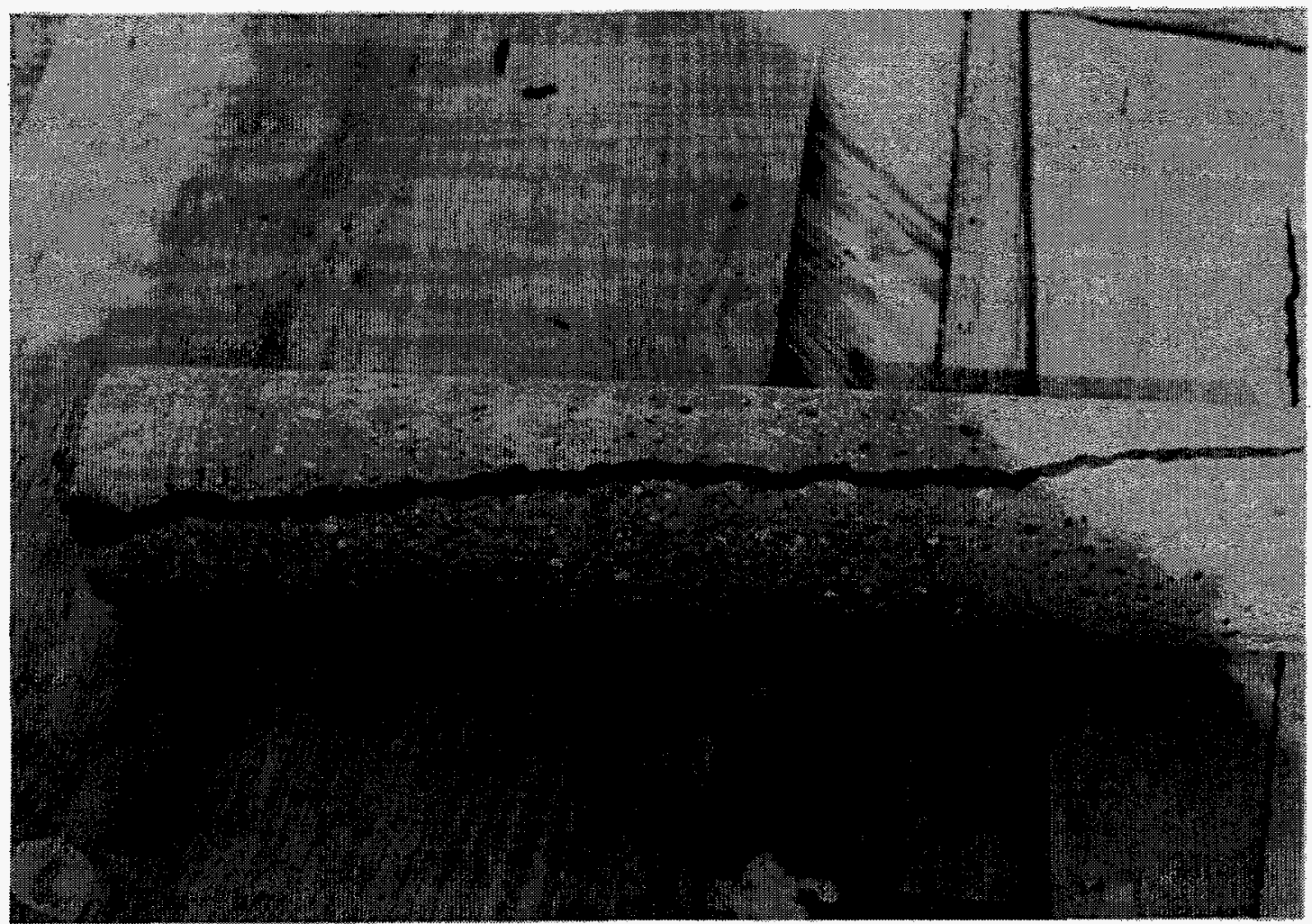

Figure 14. Core containing the hairline fracture. Fracture highlighted with water for greater visibility.

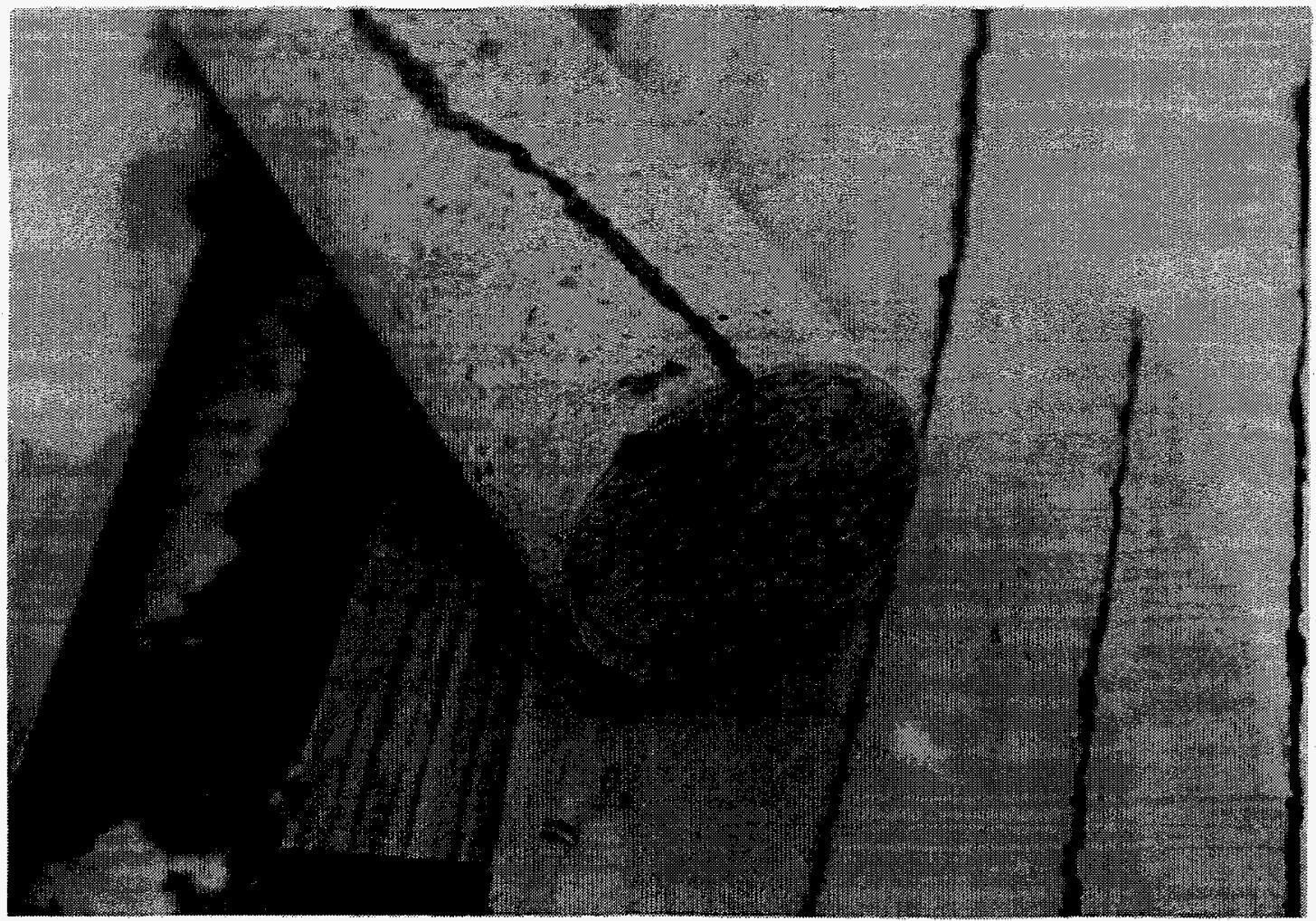

Figure 15. End of the core containing the hairline fracture. Fracture highlighted with water for greater visibility. 


\section{PERMEABILITY}

The EPA has mandated hydraulic conductivity requirements for the barriers of certain waste disposal sites. The maximum hydraulic conductivity requirement for hazardous waste site barriers is $1 \times 10^{-1}$ $\mathrm{cm} / \mathrm{s}^{1}$ Consequently, the BWCS barrier material must either meet the EPA requirement or be developed to do so before approval for field application.

Closely related to the hydraulic properties of the material itself are the hydraulic properties of a stopstart joint. A stop-start joint is the junction created whenever the barrier injection process is stopped and restarted due to equipment failure or some other field emergency. Such a stop and restart produces a joint between the two sections of barrier material that is a potential zone of weakness and barrier failure. The joint failure mechanism of primary concern is the formation of fractures, voids, and similar open-space features due to imperfect adhesion or lack of contact between the two surfaces. Such features may produce channel ways for movement of contaminated groundwater and thus defeat the waste containment barrier.

In situ air permeability measurements were taken of a stop-start joint and of a homogenous portion of the field test slab. ${ }^{8}$ Also, laboratory hydraulic conductivity measurements were made on samples collected from the BWCS field test. Similar measurements were made on baseline materials prepared at the INEEL MTL.

\subsection{Air Permeability Measurements}

A stop-start boundary in the test barrier was characterized with respect to fluid flow (and also compressive strength) by measuring the air permeability of the material containing the joint and comparing the value with a similar measurement made in a homogeneous portion of the test slab. The measurement of air permeability was chosen because the measurements can be made in situ and much more rapidly, minutes versus weeks, than other common fluids such as water. ${ }^{9,10,11,12}$ Air permeability was calculated from the pressure needed to evacuate air at a measured rate from the test slab. The air flow was through the walls of bore holes in the slab.

Although the measurements of air flow, temperature, and pressure (discussed below) are made with excellent precision (generally $\pm 1 \%$ or less), the resulting permeability values are judged to be qualitative for several reasons. Because the measurements are made in only a single 3 -in, diameter bore hole, the data may not be representative of the slab. The measurements are made in situ, under field conditions, which invites equipment malfunction, particularly imperfect fluid-tight seals against the chalky bore hole walls. The stop-start joint interface may be fragile compared to the rest of the slab, and the act of drilling the hole or making the measurement may cause the joint to fail, thus providing anomalous data. The data are difficult to quantitatively interpret because the joint is an interface between two blocks and is not a homogeneous material as assumed by the methods used to compute the permeability values from test data. Finally, no one has previously produced or characterized such a joint, and no data exist for estimating its properties. Therefore, choosing the optimum method as well as instrument range and sensitivity for measuring the joint permeability is very uncertain. In this instance, a hydraulic conductivity of $1 \times 10^{-7} \mathrm{~cm} / \mathrm{s}$ was assumed as a reasonable value for comparison, and the method and instruments were optimized for this value. The $1 \times 10^{-7} \mathrm{~cm} / \mathrm{s}$ value was selected because it is the EPA maximum limit for hazardous waste landfill barriers. ${ }^{\prime}$

In summary, the objective of the air permeability test was to provide a measurement of the permeability of the barrier material that contained a start-stop joint, while subjecting the test slab to the least possible disturbance. 


\subsubsection{Air Permeability Field Method and Observations}

Air permeability measurements were made June 25,1997 , in two core-drilled holes in a 1-ft-thick slab of the Test Run \#2 material produced by the POP BWCS ${ }^{8}$ buried tests. Three measurements were made in each hole. One hole was centered on the overnight stop-start joint between Test Run \#1 and Test Run \#2 and was located 60 in. from each side of the slab. The second hole was located in the center of Test Run \#2, about 17 in. from the core hole through the stop-start joint, and equidistant from the sides of the slab. The location of the holes/cores was chosen by field personnel after careful examination of the excavated and cleaned slab. The locations were free of recognizable defects and, at each of the two locations, a 3-in. core was drilled through the slab. The cores were recovered, including the core across the stop-start joint (Figure 16). The cores were carefully labeled and stored for laboratory permeability measurements and compressive strength testing. All of the air permeability measurements were completed before any other core drilling, sample sawing, or other activities involving the slab in order to disturb the stop-start joint as little as possible and thus minimize inadvertent damage to the joint.

\subsubsection{Apparatus}

The air permeability measuring apparatus consisted of:

- Vacuum air pump.

- Differential pressure transducer with range 0 to $25 \mathrm{psi}$

- Electronic flow meter with range 0 to $300 \mathrm{~cm}^{3} / \mathrm{min}$

- Pressure transducer designed to measure atmospheric pressure

- Thermocouple

- Voltage stabilizers to power pressure transducer and flow meter above

- Electronic data logger

- Portable computer

- Plumbing, electrical, and other hardware to connect system

- Air permeability cell.

The air permeability cell consists of two 3-in. diameter steel end-plugs separated by a spool-shaped spacer 6 in. long (see Figures 17 and 18). The bore hole interior was sealed from external air by the end plugs, but the interior wall of the bore hole was clean and open to the interior of the cell. One end of the cell was fitted with a connector so that air could be pumped into or evacuated from the cell.

The bore holes were very carefully cleaned and dried before installation of the air permeability measurement cell. The bore holes were initially cleaned using a dry cloth and brush to remove dirt, grease, cuttings, etc. The bore hole surface was then washed with acetone and dried using a clean, dry cloth and paper cleaning tissue.

The end plugs were sealed into the bore hole using epoxy jell cement (Brownells Inc. Montezuma, Iowa). About $50 \mathrm{~mL}$ of epoxy was prepared according to the manufacturer's instructions for each cell. All preparation for cell installation was carried out before the epoxy was prepared, and only enough epoxy for one cell was prepared at a given time. Each cell was carefully inserted into the bore hole to the midpoint of the slab, care being taken so that no epoxy coated the bore hole walls. Each cell was a very close, push fit into its bore hole. The cell closure was then made by compression nuts on each cell so that the epoxy was extruded into contact with the bore hole walls. After installation, the cement cured overnight. 


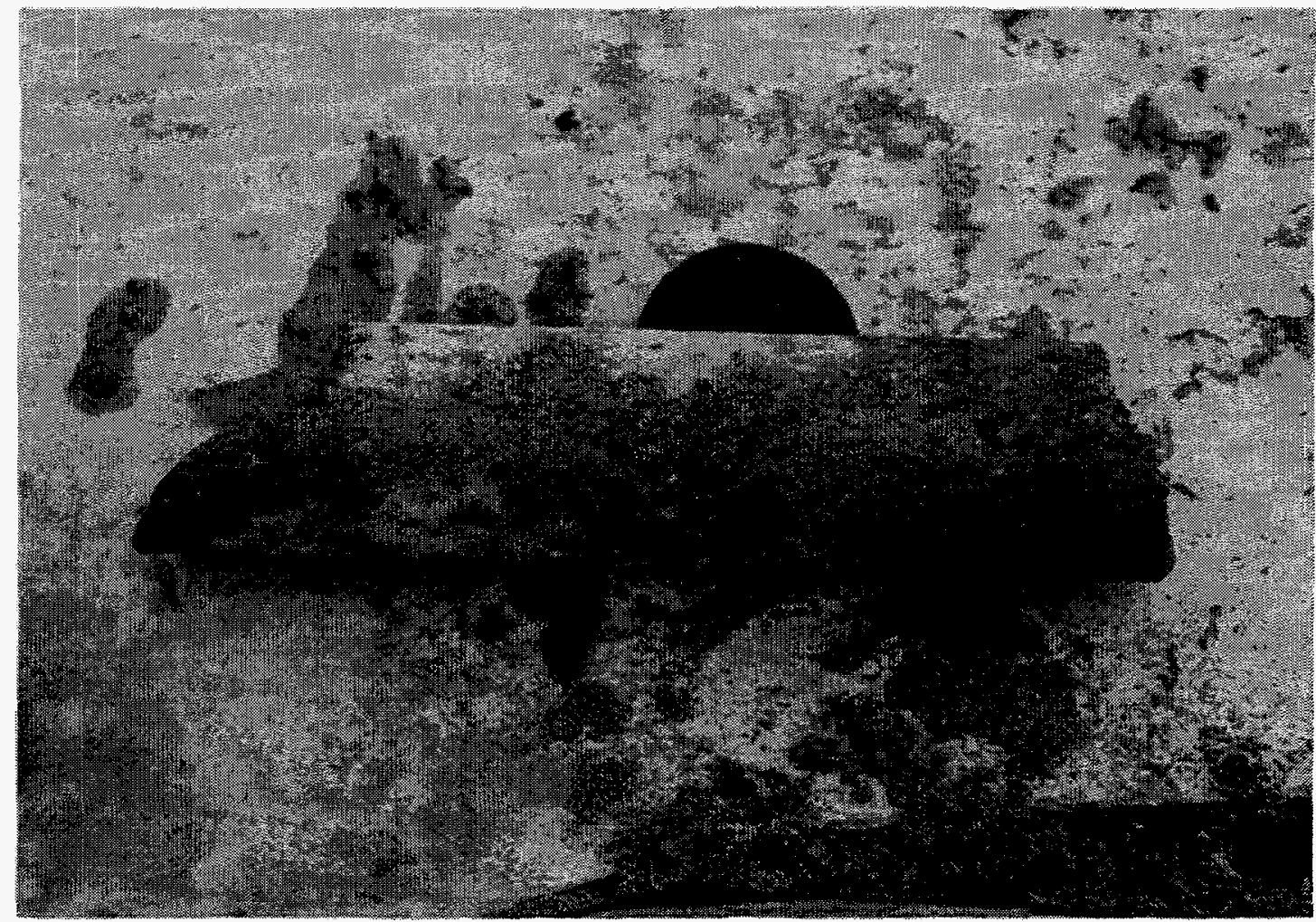

Figure 16. Core containing the stop-start joint. The joint interface is the surface between the white and red material.

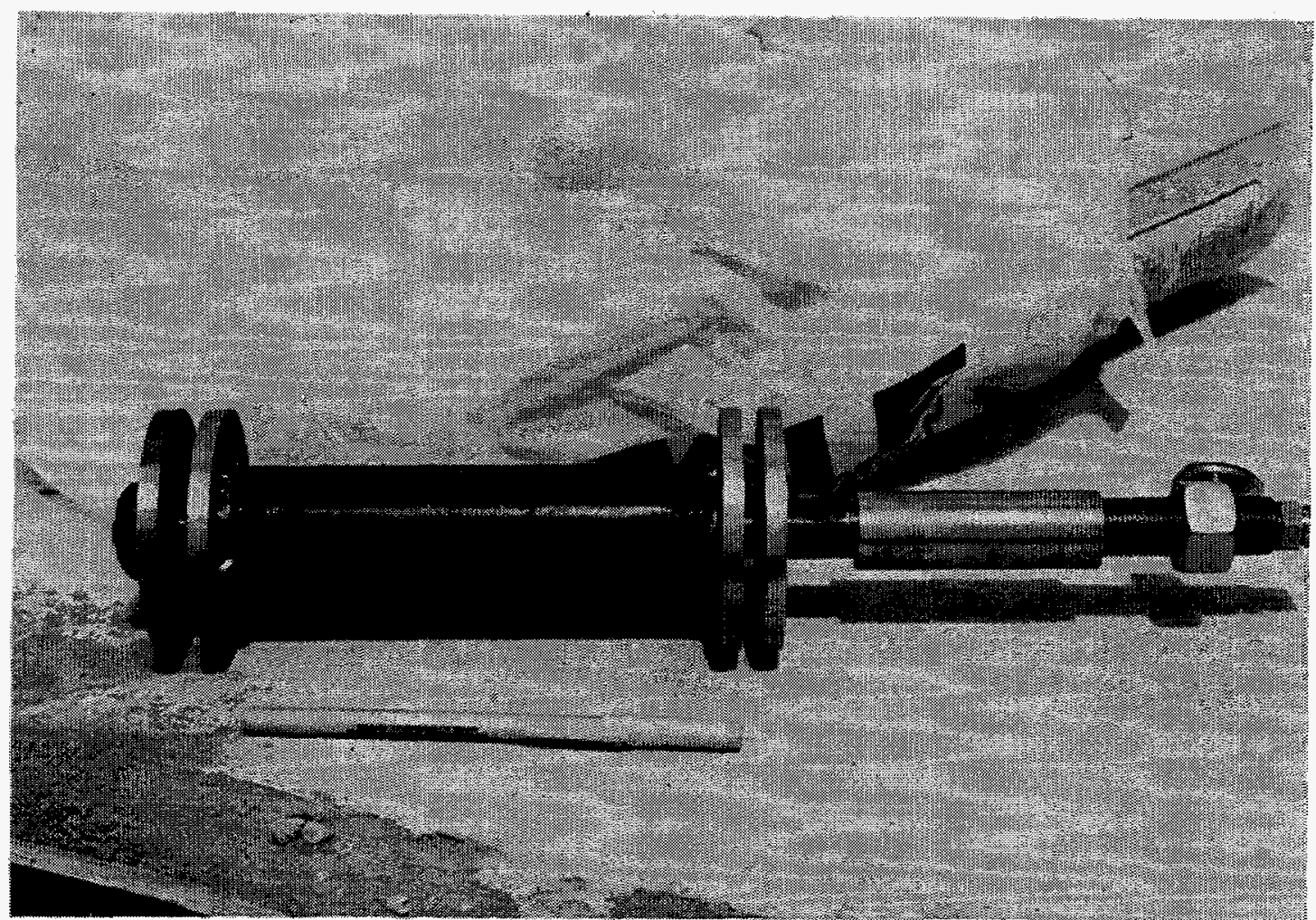

Figure 17. Air permeability cell in the open position so that sealant is not squeezed from between end plates during insertion of cell into test hole. 


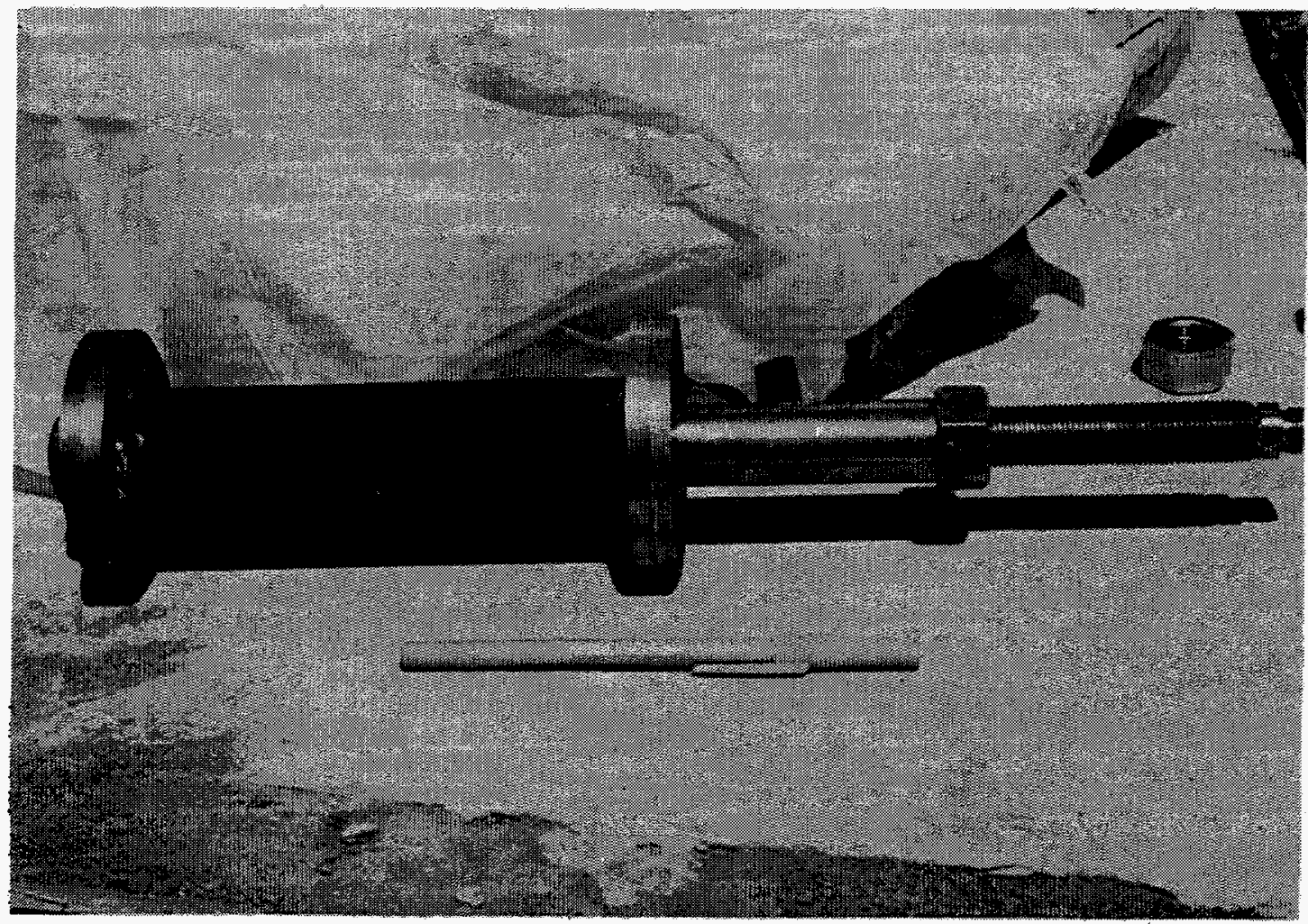

Figure 18. Air permeability cell in the closed position to squeeze sealant from between end plates.

The apparatus was assembled and operated according to the manufacturer's recommendations to measure and record temperature, air flow, and pressure as required in the permeability cell (see Figure 19). Air flow was measured as a function of differential pressure, i.e., the difference between atmospheric pressure and pressure in the cell. Air temperature within the cell was also measured. Air flow measurements at three pressures were made. All measurements were at pressures below one atmosphere. Air flow was adjusted so that each successive set of measurements was about half (or double) the flow of the preceding set of measurements.

The data measured and recorded during each test run included ambient atmospheric pressure, the steady-state air flow at a given differential air pressure, and the temperature of the air within the cell during the run. Steady state is the condition when differential pressure and flow achieve constant values, $\pm 5 \%$, for 1 minute. In general, data were recorded electronically for 10 minutes for each set of measurements. The data for a given set of measurements were also recorded manually in the field note book at 30-second intervals as backup information in case of damage to the electronically stored data.

When the measurements were completed, the data from the homogeneous portion of the slab indicated very low pressure drawdown at all tested flow rates. Therefore, both cells were checked for air leaks. This was done by pressurizing each cell with about 5 psi air, filling the volume in the slab above the cell with water, and examining the water for air bubbles. The cell across the stop-start joint appeared to bubble slightly at the epoxy boundary, but not through the joint. No bubbles were observed in the water above the second cell when it was pressurized. The lack of bubbles when pressure checked, together with the virtual lack of draw-down pressure, suggested that the bottom seal was leaking. Therefore, a block measuring 14 in. $x 14$ in. $x 3 \mathrm{ft}$ and containing both air permeability cells was cut from the slab using concrete saws and shipped to the INEEL MTL for additional testing and observation. 


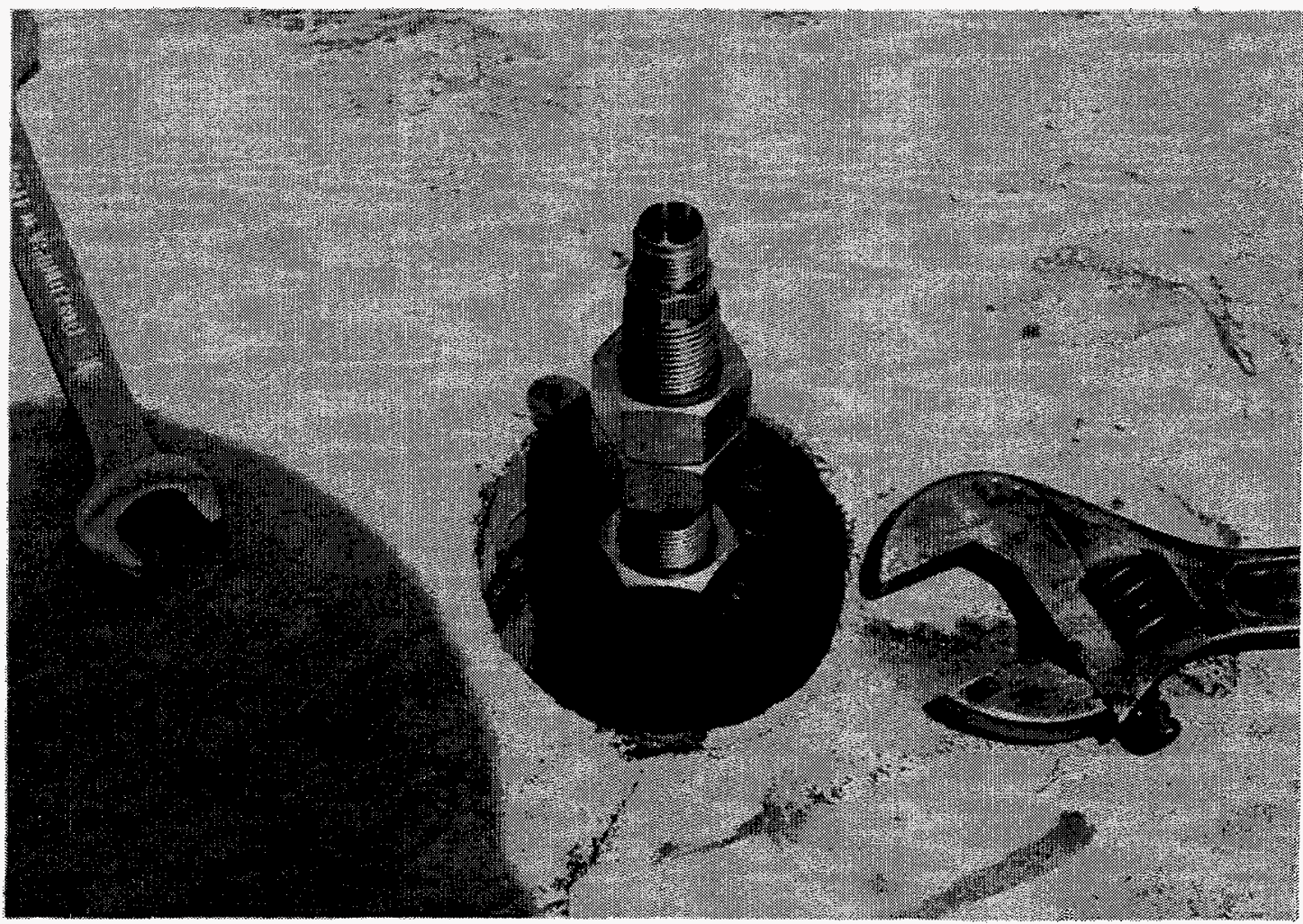

Figure 19. Air permeability cell in operating position in the BWCS Test Run \#2 test slab.

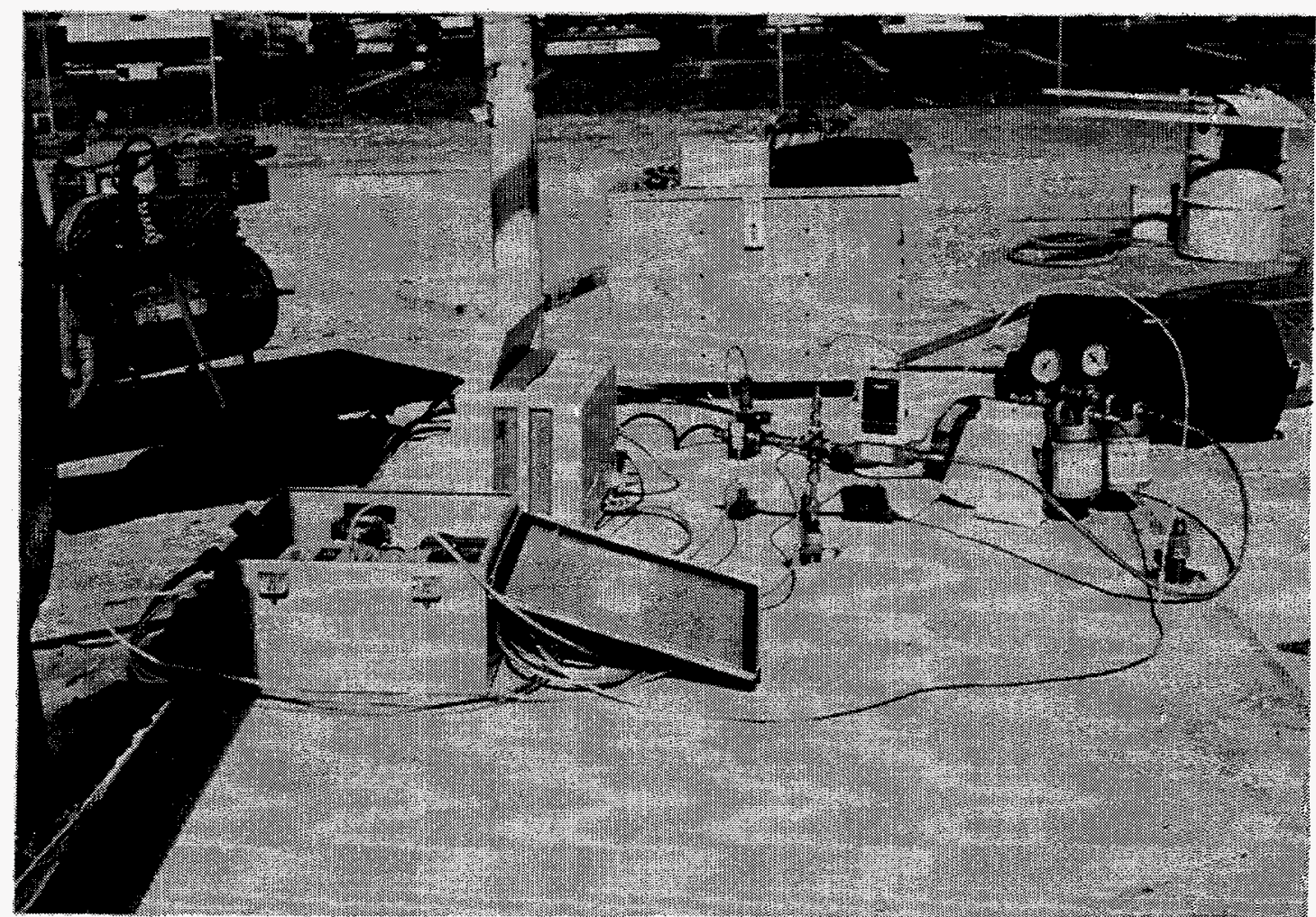

Figure 20. Air permeability cell instrumentation and layout. 
Inspection at the INEEL indicated that the bottom seal of the cell in the homogeneous material was probably not sealed. The bottom hole-wall to cell end-plate junction of both holes was resealed by coating with household epoxy cement and allowed to cure overnight. The air permeability measurements were then repeated using the same method and apparatus as used at the field site. The tests at the INEEL were partially successful. Measurements were made of the bore hole in the homogeneous material. However, pressure drawdown was not achieved on the bore hole containing the stop-start joint; therefore, measurements were not completed. The lack of pressure drawdown suggests that damage to the joint had occurred during collection and transport to the INEEL.

Examination of the block indicated that voids were present in the barrier material within 2 to 3 in. of the stop-start joint surface. Two voids were observed on the saw cut surface of the block. Both were lens shaped, with the long axis roughly parallel to the top surface of the slab and up to about 0.25 in. wide. Lengths of the voids were about 3 and 6 in.

\subsubsection{Air Permeability Calculation}

4.1.3.1 Governing Equation. The following equation ${ }^{13}$ was used for calculating the permeability of the samples for each of the six sets of pressure and airflow measurements.

$$
k=\left(Q_{v} m / L\right)\left(P_{d} /\left[P_{a t m}^{2}-P d^{2}\right]\right) \ln \left(r_{i} / r_{w}\right)
$$

where

$$
\begin{aligned}
& \mathrm{k}=\text { permeability }\left(\mathrm{cm}^{2}\right) \\
& \mathrm{Q}_{\mathrm{v}}=\text { volumetric airflow rate }(\mathrm{cm} / \mathrm{s}) \\
& \mathrm{m}=\text { dynamic viscosity of air }\left(\mathrm{dyne}-\mathrm{s} / \mathrm{cm}^{2}\right) \\
& \mathrm{P}_{\mathrm{d}}=\text { draw down pressure }\left(\mathrm{dyne} / \mathrm{cm}^{2}\right) \\
& \mathrm{P}_{\mathrm{atm}}=\text { atmospheric pressure }\left(\text { dyne } / \mathrm{cm}^{2}\right) \\
& \mathrm{r}_{\mathrm{i}}=\text { steady state radius of influence }(\mathrm{cm}) \\
& \mathrm{r}_{\mathrm{w}}=\text { radius of well }(\mathrm{cm}) \\
& \mathrm{L}=\text { length (width) of the producing formation (screened interval) }(\mathrm{cm}) .
\end{aligned}
$$

This equation is for single-phase, radial-fluid flow to a well completed in a reservoir that is homogeneous, horizontal, and of uniform thickness. The fluid is assumed to be compressible, isothermal, and behave as an ideal gas. Use of this formula requires an estimate for the steady-state radius of influence, $r_{1}$, the point at which the drawdown pressure is equal to atmospheric pressure. In the case of a cylindrical withdrawal area, the radius of influence is approximately equal to the length of the producing formation ${ }^{14}$ (i.e., the distance between the cell end plugs). This assumption has been shown to be valid for $L / r_{w} \geq 16$. For smaller ratios of $L / r_{w}$, as in this case where $L / r_{w}=4$, the $r_{1}$ will be less than $L$ and thus the model will overestimate permeability. For illustration purposes, if $r_{1}$ were $L / 2$, which would be only 3 in. in this case, then the permeability would be overestimated by a factor of two. This demonstrates the insensitivity of the calculation to $r_{1}$.

4.1.3.2 Estimating Steady State Pressure and Flow. Pressure and flow data from the tests were recorded as a function of time. During tests of the homogeneous material, the electronic data logger recorded transient pressure and flow data before a quasi steady-state drawdown condition was obtained. A steady-state drawdown condition was determined by visual examination of the data. Time intervals were selected, and the data within the intervals were averaged to determine average pressure and flow for that test. For the remaining tests, i.e., the measurements made of the stop-start joint, all the data for each test were used. In these cases, the electronic data logger was started after the vacuum pump and other apparatus were operating. 


\subsubsection{Results and Discussion}

Permeability and hydraulic conductivity results for six measurements are shown in Table 7 . Also presented are the average steady-state pressure and flow data. Hydraulic conductivity was estimated from the permeability values using water properties at $20^{\circ} \mathrm{C}$.

The hydraulic conductivity of the borehole through the stop-start joint was approximately $8.6 \times 10^{-7}$ $\mathrm{cm} / \mathrm{s}$. The observation of traces of air bubbles during the leak check, as well as the model computation assumptions (see above), indicate that the computed values are maximum estimates of the hydraulic conductivity of the material containing the stop-start joint. In the case of the core hole in the homogeneous material, measurements carried out at the INEEL indicate an average hydraulic conductivity of $8.6 \times 10^{-9} \mathrm{~cm} / \mathrm{s}$ for the homogeneous material of Test Run \#2. Both values are in very good agreement with the laboratory-measured hydraulic conductivity, $1.1 \times 10^{-8} \mathrm{~cm} / \mathrm{s}$ (stop-start joint) and $1.6 \times 10^{-10} \mathrm{~cm} / \mathrm{s}$ (average homogeneous material).

\subsection{Hydraulic Conductivity}

Ten core samples were selected for laboratory hydraulic conductivity measurements. Four of these were cores taken from the BWCS buried Test Run \#2. Four were cores diamond drilled from the baseline flexure beams prepared in the INEEL MTL. One sample was the core drilled through the crack observed in the BWCS buried Test Run \#2 (Figure 14), and one sample was the core drilled through the overnight stop-start joint (see air permeability measurements above). Baseline samples were core drilled from test beams so that the samples had similar preparation histories.

Table 7. Permeability and hydraulic conductivity results from air permeability.

\begin{tabular}{lcccc}
\hline \multicolumn{1}{c}{ Test } & $\begin{array}{c}\text { Average Pressure, } \\
\text { Drawdown, } \mathrm{P}_{\mathrm{d}} \\
(\mathrm{psi})\end{array}$ & $\begin{array}{c}\text { Average Flow, } \mathrm{Q}_{\mathrm{v}} \\
\left(\mathrm{cm}^{3} / \mathrm{s}\right)\end{array}$ & $\begin{array}{c}\text { Permeability } \\
\left(\mathrm{cm}^{2}\right)\end{array}$ & $\begin{array}{c}\text { Hydraulic } \\
\text { Conductivity } \\
(\mathrm{cm} / \mathrm{s})\end{array}$ \\
\hline $\begin{array}{l}\text { Homogeneous Material } \\
\text { Trial }{ }^{2} \text { Number } \\
\text { BWCS-7 }\end{array}$ & & & & \\
BWCS-8 & 8.07 & 2.23 & $8.6 \times 10^{-14}$ & $8.5 \times 10^{-9}$ \\
BWCS-9 & 8.53 & 3.03 & $1.1 \times 10^{-13}$ & $1.1 \times 10^{-8}$ \\
Average & 9.04 & 1.78 & $6.5 \times 10^{-14}$ & $6.4 \times 10^{-9}$ \\
& & & & $8.6 \times 10^{-9}$ \\
Joint Trial Number & & & & \\
BWCS-4 & 10.47 & 36.25 & $8.1 \times 10^{-12}$ & $8.0 \times 10^{-7}$ \\
BWCS-5 & 6.64 & 70.49 & $8.6 \times 10^{-12}$ & $8.4 \times 10^{-7}$ \\
BWCS-6 & 8.95 & 83.76 & $9.6 \times 10^{-12}$ & $9.4 \times 10^{-7}$ \\
Average & 5.95 & & $8.6 \times 10^{-7}$ \\
\hline \\
a. Measurements carried out at the INEEL.
\end{tabular}


At the present time (9/30/97), quantitative hydraulic conductivity measurements of nine specimens have been completed and are shown in Table 8. Five are core samples from the BWCS buried Test Run \#2, three are cores from the homogeneous material, one is the core sample of the stop-start joint (Figure 16), and one is the core sample of the fracture (Figure 15). The remaining four samples are baseline materials prepared at the CFA.MTL (see Section 5.1.2).

\subsubsection{Method}

Measurements were made to determine the hydraulic conductivity $(\mathrm{k})$ of the BWCS barrier materials and were performed in accordance with ASTM 5084-90, the standard test method for measuring $k$ of water saturated porous materials using a flexible wall permeameter. All test specimens were 2.75-in. diameter drill core specimens. The measurements were made by a commercial laboratory, Shannon $\&$ Wilson, Inc., Richland, WA.

\subsubsection{Results}

The results of the hydraulic conductivity measurements show that the homogenous barrier material had a hydraulic conductivity of about $1.6 \times 10^{-10} \mathrm{~cm} / \mathrm{s}$, and the materials containing the stop start joint had a hydraulic conductivity of about $1.1 \times 10^{-8} \mathrm{~cm} / \mathrm{s}$. The material containing the hairline fracture had a hydraulic conductivity of $1.2 \times 10^{-5} \mathrm{~cm} / \mathrm{s}$.

\subsection{Permeability Summary}

The hydraulic conductivity values determined from air permeability measurements agree very well with the results obtained from the laboratory hydraulic conductivity data.

The results indicate that material in the overnight stop-start joint as well as the barrier materials in the BWCS buried Test Run \#2 exceed the EPA hydraulic conductivity standard of $10^{-7} \mathrm{~cm} / \mathrm{sec}$. The material containing the stop-start joint has a hydraulic conductivity of $1.1 \times 10^{-8} \mathrm{~cm} / \mathrm{s}$, and the BWCS buried Test Run $\# 2$ has an average hydraulic conductivity of about $1.6 \times 10^{-10} \mathrm{~cm} / \mathrm{s}$. These results are confirmed by the air permeability measurements of $8.6 \times 10^{-7} \mathrm{~cm} / \mathrm{s}$ for the stop-start joint and $8.6 \times 10^{-9}$ $\mathrm{cm} / \mathrm{s}$ for the homogeneous barrier material.

Table 8. Laboratory-measured hydraulic conductivity.

\begin{tabular}{ll} 
Sample Number & $\begin{array}{c}\text { Hydraulic Conductivity } \\
(\mathrm{cm} / \mathrm{s})\end{array}$ \\
\hline Core Sample & $8.8 \times 10^{-11}$ \\
$\# 7^{2}$ & $1.9 \times 10^{-10}$ \\
$\# 8^{\mathrm{a}}$ & $1.9 \times 10^{-10}$ \\
$\# 11^{\mathrm{a}}$ & $1.6 \times 10^{-10}$ \\
Average & $1.2 \times 10^{-5}$ \\
$\# 16^{\mathrm{b}}$ & $1.1 \times 10^{-8}$ \\
$\# 1^{\mathrm{c}}$ & \\
Baseline Sample & $1.1 \times 10^{-9}$ \\
1 & $1.3 \times 10^{-9}$ \\
2 & $1.3 \times 10^{-9}$ \\
3 & $1.8 \times 10^{-9}$ \\
4 & \\
\hline & \\
a. Homogeneous barrier materials in the BWCS buried Test Run \#2. \\
b. Core through the fracture in Test Run \#2. \\
c. Core through the stop-start joint.
\end{tabular}




\section{MECHANICAL PROPERTIES OF FIELD AND BASELINE BARRIER MATERIAL}

Two batches of material having a composition similar to the BWCS buried Test Run \#2 barrier were prepared at the INEEL MTL to provide a standard (baseline) for comparison to the materials prepared during the BWCS field test program. A set of mechanical properties were measured for both the baseline material and the material from the BWCS buried Test Run \#2. The preparation of the baseline materials and the results of the mechanical property test are described in this section. Also included in this section are petrographic (modal) analyses of both field and baseline samples. The modal analyses were carried out to assess separation and segregation of the barrier materials.

\subsection{Mechanical Property Tests}

A set of mechanical property measurements were made on specimens collected from the BWCS buried Test Run \#2 and on materials prepared at the INEEL MTL. The tests were intended to show if the BWCS emplacement process affected the properties of the barrier material. The measurements included:

- Compression testing-ASTM C-39

- Tensile (splitting strength)-ASTM C-496

- Porosity, specific gravity, and air voids-ASTM C-642

- Modulus of elasticity (creep)-ASTM C-469 Static Test

- Modulus of rupture (flexural)-ASTM C-78.

All mixture preparation and material testing was carried out at the INEEL MTL at Central Facilities Area Building 602.

\subsubsection{BW/CS Material Preparation}

The BWCS buried Test Run $\# 2$ cores were 2.75 in. in diameter and were trimmed, using a modified masonry saw, to a length of twice the diameter, 5.50 in The beam samples were trimmed to a final dimension of $6 \times 6 \times 21$ in.

\subsubsection{Baseline Concrete Material Preparation}

The materials used to prepare the test mixtures included the following:

- Rapid Set cement, manufactured by the CTS Cement Manufacturing Company

- Latex, Modifier A, Lot LB23017220, manufactured by the Dow Chemical Company

- Concrete sand-ASTM C-33, Fine Aggregate

- Food-grade citric acid

- Tap water at Central Facilities Area Building 602.

The ingredients were added to a rotating drum cement mixer. Rapid Set cement and sand were drymixed followed by the latex emulsion, then citric acid and water. Liquids were added last to the cement, initiating the reaction. Two different mixtures with similar compositions were prepared.

A Speed King drum-type mixer was used to mix both batches. This mixer is a $3-\mathrm{ft}^{3}$ drum with mixing fins, not paddles. This type of mixing apparatus is standard for the development of mix designs of normal concrete mixes, and it keeps the amount of trapped air as low as possible. 
The mixtures were molded into standard cylinders 6 in. in diameter and 12 in. long and into beams $6 \times 6 \times 21$ in. A release agent was placed on the molds to aid sample removal. All of the cylindrical samples were placed into a curing tank/chamber and the temperature/humidity were monitored throughout the 28 -day curing time. The tank averaged about $70^{\circ} \mathrm{F}$ and $80 \%$ plus humidity to simulate field curing conditions. The four flexural beam samples were placed on a rack near the curing tank. This area remained at ambient room temperature and humidity for the 28-day cure time. Cores measuring 3 in. in diameter and 6 in. long were drilled from the beam fragments for hydraulic conductivity measurements after the flexural test had been completed.

The following test equipment was used:

- Balance $\mathrm{kg}$ range

- Drum cement mixer (Speed King)

- $100,000-1 b$ compression, modulus of elasticity and flexural tester (Tinius Olsen)

- Environmental chamber and drying oven

- Slump test cone and tray

- Standard ASTM $3 \times 6$ 6-in. and 6 x 12-in. cylindrical molds

- Standard ASTM $6 \times 6 \times 21$-in. beam molds.

\subsubsection{Mixing Results}

Testing of the mix design began on June 10,1997 . The trial mixes were prepared as closely as possible to the mix design of the as-mixed composition BWCS buried Test Run \#2. The mix proportions for Batch 1 are shown in Table 9.

After mixing for 5 to 6 minutes, Batch 1 had a slump of 8 in, as measured with a calibrated slump cone, and a mix temperature of $72^{\circ} \mathrm{F}$. Stiffening of this mix began within 15 minutes, but initial set was clearly different from the BWCS field batches (see Section 3) in that it appeared to take longer to achieve 20 psi compressive strength. It should be noted that the day this mix was produced was a rainy, cool day with humidity in the 75 to $100 \%$ range. The ambient air temperature at the time of mixing was 55 to $60^{\circ} \mathrm{F}$.

From this initial mix, one set of four $6 \times 12$-in. cylinders and one set of four $2 \times 4$-in. cylinders were cast. Also from this first batch, four standard $6 \times 6 \times 21$-in. flexural beams were cast.

The second mix had a slump, measured about 6 minutes after adding water, of 7.75 in., and a mix temperature of $76^{\circ} \mathrm{F}$. The stiffening of Batch 2 also occurred in 15 to 20 minutes; however, as with the first batch, set did not occur for approximately 2 to 3 hours. Mix proportions for the second batch are shown in Table 10.

Table 9. Baseline mix composition for Batch 1.

\begin{tabular}{lccc}
\hline \multicolumn{1}{c}{ Component } & $\begin{array}{c}\text { Weight } \\
(\mathrm{lb})\end{array}$ & Wt\% & Per 100 Parts Cement \\
\hline Cement, Rapid Set & 88.00 & 22.3 & 100 \\
Concrete sand ASTM C33 & 256.50 & 65.0 & 291 \\
Latex (solids), Dow Chemical Co., & 13.78 & 3.49 & 15.7 \\
Mod. A, Lot No. LB23017220 & & & \\
Citric acid & 0.35 & 0.09 & 0.40 \\
Total water & 36.3 & 9.2 & 41.3 \\
Totals & 394.9 & & \\
\hline
\end{tabular}


Table 10. Baseline mix composition Batch 2.

\begin{tabular}{lccc}
\multicolumn{1}{c}{ Component } & $\begin{array}{c}\text { Weight } \\
(\mathrm{lb})\end{array}$ & Wt\% & Per 100 Parts Cement \\
\hline Cement, Rapid Set & 76.80 & 22.16 & 100 \\
Concrete sand ASTM C33 & 223.87 & 64.6 & 291 \\
Latex (solids), Dow Chemical Co., & 12.03 & 3.47 & 15.7 \\
Mod. A, Lot No. LB23017220 & & & \\
Citric acid & 0.31 & 0.09 & 0.40 \\
Total water & 33.5 & 9.67 & 43.6 \\
Totals & 346.5 & & \\
\hline
\end{tabular}

From the second trial batch, three sets of four cylinders ( $6 \times 12$ in.) were cast. Also, from this second batch, one set of four cylinders $(2 \times 4$ in.) were cast.

\subsubsection{Mechanical Property Results}

The results of the mechanical testing of the laboratory cast samples and the BWCS buried Test Run \#2 materials are summarized below. The term "core" refers to drill core samples from BWCS Buried Test \#2, and "cylinder" refers to samples prepared at the MTL.

The mechanical property measurements of the baseline materials prepared at the MTL provide a standard of comparison for similar measurements made on the BWCS barrier material. A comparison of the two set of data indicate that the two materials are usually noticeably different, sometimes very different. In general, the baseline material has lower specific gravity (1.93 versus 2.19 -Table 11$)$, lower compressive strength, (1,861 psi versus 5,241 psi-Table 12$)$, lower modulus of elasticity (403,000 psi versus $2,970,000 \mathrm{psi}$-Table 13), lower tensile strength (143 psi versus $200 \mathrm{psi}$-Table 14), and slightly higher flexural strength (688 psi versus 604-Table 15$)$.

Table 11. Porosity, specific gravity, and air voids-ASTM C-642.

\begin{tabular}{|c|c|c|c|c|c|c|c|}
\hline \multirow[b]{2}{*}{ BWCS Core \# } & \multicolumn{3}{|c|}{ Specific Gravity } & \multirow{2}{*}{$\begin{array}{c}\text { MTL } \\
\text { Cylinder } \#^{\mathrm{b}}\end{array}$} & \multicolumn{3}{|c|}{ Specific Gravity } \\
\hline & Dry & $S S S D^{a}$ & Apparent & & Dry & SSD & Apparent \\
\hline 8 & 2.18 & 2.28 & 2.44 & 9 & 1.97 & 2.09 & 2.24 \\
\hline 9 & 2.21 & 2.30 & 2.45 & 10 & 1.97 & 2.08 & 2.21 \\
\hline 10 & 2.17 & 2.28 & 2.43 & 11 & 1.91 & 2.03 & 2.17 \\
\hline 11 & 2.19 & 2.28 & 2.42 & 12 & 1.87 & 2.03 & 2.22 \\
\hline Average & 2.19 & 2.29 & 2.44 & & 1.93 & 2.06 & 2.21 \\
\hline BWCS Core \# & $\begin{array}{l}\text { Porosity } \\
\text { (vol\%) }\end{array}$ & & $\begin{array}{l}\begin{array}{l}\text { Void } \\
\text { (vol\%) }\end{array} \\
\end{array}$ & $\begin{array}{c}\text { MTL } \\
\text { Cylinder } \#^{\mathrm{b}} \\
\end{array}$ & $\begin{array}{c}\begin{array}{c}\text { Porosity } \\
(\mathrm{vol} \%)\end{array} \\
\end{array}$ & & $\begin{array}{c}\text { Void } \\
\text { (vol\%) }\end{array}$ \\
\hline 8 & 12 & & 14 & 9 & 13 & & 14 \\
\hline 9 & 12 & & 14 & 10 & 10 & & 11 \\
\hline 10 & 12 & & 14 & 11 & 13 & & 15 \\
\hline 11 & 11 & & 13 & 12 & 16 & & 19 \\
\hline Average & 12 & & 14 & & 13 & & 15 \\
\hline
\end{tabular}


Table 12. Results of compression test-ASTM C-39.

\begin{tabular}{cccc}
\hline BWCS Core \# & psi & Cylinder \# & psi \\
\hline $1^{\mathrm{a}}$ & 5,014 & & \\
15 & 5,286 & 1 (Batch 1) & 2,300 \\
2 & 5,315 & 2 (Batch 1) & 2,210 \\
4 & 5,215 & 3 (Batch 2) & 1,485 \\
5 & 5,148 & 4(Batch 2) & 1,450 \\
Average: & 5,241 & Average: & 1,861 \\
\hline
\end{tabular}

a. Core through the overnight stop start junction material. This value was not included in the average.

Table 13. Modulus of elasticity results-ASTM C-469.

\begin{tabular}{|c|c|}
\hline Sample \# & $\begin{array}{l}\text { Modulus of } \\
\text { Elasticity }\end{array}$ \\
\hline $1^{a}$ & 460,000 \\
\hline $2^{a}$ & 450,000 \\
\hline $3^{a}$ & 300,000 \\
\hline Average & 403,000 \\
\hline $4^{b}$ & $1,050,000$ \\
\hline $5^{\mathrm{c}}$ & $2,980,000$ \\
\hline $5^{c}$ & $2,940,000$ \\
\hline $6^{c}$ & $2,950,000$ \\
\hline $6^{\mathrm{c}}$ & $3,010,000$ \\
\hline Average & $2,970,000$ \\
\hline \multicolumn{2}{|c|}{$\begin{array}{l}\text { a. Cast sample prepared at the MTL. } \\
\text { b. Cast sample prepared at the MTL, but previously heated to } 105^{\circ} \mathrm{C} \text { for } 24 \text { hours. Not included in average values. } \\
\text { c. Core sample cut from BWCS buried Test Run } \# 2 \text {, air permeability test block. } \\
\text { d. Core sample cut from BWCS buried Test Run } \# 2 \text { flexural beam. }\end{array}$} \\
\hline
\end{tabular}

Table 14. Results of tensile strength test (splitting strength)-ASTM C-496.

\begin{tabular}{cccc}
\hline BWCS Core \# & psi & Cylinder \# & psi \\
\hline 4 & 198 & 5 (Batch 1) & 138 \\
5 & 214 & 6 (Batch 1) & 137 \\
9 & 221 & 7 (Batch 2) & 148 \\
10 & 169 & 8 (Batch 2) & 150 \\
Average: & 200 & Average: & 143 \\
\hline
\end{tabular}


Table 15. Results of flexural test (modulus of rupture)-ASTM C-78.

\begin{tabular}{|c|c|c|c|}
\hline Beam \# ${ }^{a}$ & psi & Beam \# & psi \\
\hline 30 & 607 & 1 & 695 \\
\hline 31 & 588 & 2 & 715 \\
\hline 32 & 593 & 3 & 661 \\
\hline 33 & 627 & 4 & 680 \\
\hline Average & 604 & Average & 688 \\
\hline
\end{tabular}

The data indicate that some of the differences are probably due to the mixing apparatus. The field materials were prepared in a commercial continuous mixer (see Section 3.1), whereas the baseline samples were prepared in a cylindrical rotary mixer. The result is more air entrainment in the baseline samples because they were mixed longer, about 6 minutes versus 1 minute or less, and the rotary motion of the cylindrical mixer may tend to entrain more air than the auger of the continuous mixer. The increased air content is indicated by the lower specific gravity and the noticeably larger voids and increased porosity of the baseline samples observed during the petrographic analysis (see Section 5.2).

A second aspect is the possible difference in amount of curing of the two materials. The MTL baseline samples may not have cured to the same degree as the field samples, even though the time from mixture preparation to sample testing was about the same. This is indicated by the sharp odor of latex from the baseline samples, but none from the field samples. All of the cylindrical samples were placed into a curing tank/chamber, and the temperature and humidity were monitored throughout the 28-day curing time. The tank averaged about $70^{\circ} \mathrm{F}$ and $80 \%$ plus humidity. The four flexural beam samples were placed on a rack near the curing tank. This area remained at ambient room temperature and humidity for the 28 -day cure time. It was found that the beams, which were cured at room temperature and humidity, achieved the same or slightly higher strength than the saw cut field specimens. The cylinders, cured inside the controlled tank at a higher humidity and slightly higher temperature than the beams, produced strength results lower than the core samples from the BWCS buried Test Run \#2. Possibly related to the curing time is the difference in the order of addition of citric acid to the baseline mixtures. The citric acid was added after the latex during the preparation of the baseline materials. This may have caused the citric acid to be ineffective as a retardant and explains the short workability time, in comparison to the field materials ${ }^{8}$ of the baseline materials. It also may have affected the mixture by an acid-base reaction, resulting in destabilization of the latex emulsion. The magnitude and effect, if any, of this possible reaction are being experimentally evaluated at this time (9/97) at the MTL. The results of measurements made 14 days after mixing indicate that the mechanical properties of the baseline materials are virtually identical to the BWCS Buried Test \#2 materials if the citric acid is added to the cement before the latex is added to the mixture (see Appendix B).

Other differences between the two materials probably have much less effect. The baseline samples had slightly more water, about $42 \%$ compared to about $36 \%$ in the BWCS Test Run \#2. In general, the effect of such an increased water content is expected to be minor.

A final point concerns the compressive strength of the stop-start joint. The data indicate that the stop-start joint has strength comparable to the homogeneous BWCS material, namely 5,014 psi for the joint versus 5,241 psi for the average strength of the homogeneous BWCS Test Run \#2 material. 


\subsection{Petrographic Analysis}

During emplacement and before set, cementatious materials are often affected by the processes of separation and/or segregation. Separation refers to the gravitational separation of components in the cementatious mixture so that the final composition of the slab or other object is not homogeneous from top to bottom. Segregation also results in an inhomogeneous final product, except in this case, the segregation of components occurs due to flow processes and results in inhomogeneities in the horizontal direction. The magnitude of separation and segregation in the test barrier material produced by the POP test was evaluated by measuring the proportions of aggregate, matrix, and voids in the top and bottom of four selected core samples. If separation had occurred, the proportions of aggregate, matrix, and void in the top of a given core would be different from the proportions in the bottom of that core. If segregation had occurred, then the proportions among aggregate, matrix, and voids in one core would be different from the proportions in a second core collected at some distance from the first core.

\subsubsection{Sample Location}

Four cores were taken June 25, 1997, from the Test Run \#2 of the POP buried test series carried out at the RAHCO International test facility in Spokane, Washington. ${ }^{8}$ A core was taken from each corner of the Test Run \#2 slab, $1 \mathrm{ft}$ from the slab side and 8 in. from the stop-start joint. To an observer looking in the direction of header movement, Core \# 3 was located on the left next to the overnight stop-start joint with Test Run \#1 (the first pour of the series), Core \#6 was located on the left next to the stop-start joint (1.5 hours between pours) with Test Run \#3, Core \#15 was located on the right next to the stop-start joint with Test Run \#1, and Core \#17 was located on the right next to the stop-start joint with Test Run \#3. The distance between the stop-start joints is 37 in. as measured in the field. The side-to-side dimension of the slab is $120 \mathrm{in}$.

\subsubsection{Method}

The method is the modal analysis point count technique used to measure the mineralogy and texture of rocks. ${ }^{15}$ The precision of this type of analysis is given by the relation $\mathrm{e}= \pm 2[\mathrm{p}(1-\mathrm{p}) / \mathrm{N}]^{1 / 2}$, where $\mathrm{e}$ is the absolute error at the 0.95 confidence limit, $\mathrm{p}$ is the proportion of the constituent of interest, and $\mathrm{N}$ is the number of points. ${ }^{16}$ For each sample, about 350 to 500 points (spaced on a 0.125 -in. grid) were identified as belonging to one of three classes (aggregate, matrix, or void) by visual examination using a Bosch and Lomb 10X stereoscopic microscope. The aggregate class was defined as the material readily identifiable as particulate material; the void class was defined as open space within the sample; and the matrix class was defined as the inter-granular material containing cement gel and other material in which neither the particles nor voids could be easily resolved optically. Particles and voids smaller in diameter than 0.015 in. were usually not resolved optically, and were included in the matrix class.

Samples for analysis were obtained by cutting a section $2.75 \mathrm{in}$. in diameter and $1 \mathrm{in}$. thick from the top and bottom of each core using a water-cooled diamond saw. The sections were cut perpendicular to the core axis and about 12 in. apart. For comparison, similar sections 1 in. thick were cut from the top and bottom of two cast cylinders 6 in. in diameter and $12 \mathrm{in}$. long, which were previously used for the baseline tensile strength tests (Section 5.1.4). Just prior to each set of measurements, the surface of the sample was coated with glycerine to provide a temporary smooth surface in order to obscure saw marks and other surface roughness. This treatment enhanced observation of sample textural features. All modal analyses were carried out by a single operator using a single equipment system in order to minimize error sources. General sample preparation and examination procedures are described in ASTM C856-95. 


\subsubsection{Results}

The results are shown in Table 16. The mean value, based on about 3,000 data points, indicates that a typical sample of Test Run $\# 2$ material from the POP buried test is expected to contain $60 \pm 2$ vol\% aggregate (as defined here), $36 \pm 2$ vol\% matrix, and $4 \pm 1$ vol\% voids. The data indicate that the composition of the buried POP Test Run \#2 material is homogeneous, within the precision of the measurement method used, in both the vertical and horizontal directions. The data do not suggest that significant separation or segregation occurred during the emplacement or curing process.

The mean values of the two baseline samples prepared at the MTL are $59 \pm 2$ vol\% aggregate, $34 \pm 2$ vol\% matrix, and $7 \pm 1$ vol\% voids. No evidence of component separation was observed.

The data indicate that the proportion of aggregate in the POP material is identical to that in the baseline material within the precision of the measurements. The data suggest that the proportion of matrix may be slightly greater in the POP material ( $36 \pm 2$ vol\% versus $34 \pm 2$ vol\%), while the proportion of voids is smaller ( $4 \pm 1$ vol\% versus $7 \pm 1$ vol\%). Observation of the samples indicated distinct differences between the POP field test samples and the baseline samples. The diameter of voids in the baseline sample often exceeded 0.125 in. and were as large as 0.25 in. No voids in the POP samples were observed to exceed 0.125 in. The baseline samples absorbed glycerine much more readily than the POP samples, suggesting that the baseline samples are more porous than the POP samples. The baseline sample crumbled more readily in the hand than the POP samples and also had more grains that had pulled from the matrix during cutting, sawing, etc. The baseline samples had a strong latex odor even 2 months after sample preparation in contrast to the core samples, which did not have such an odor.

Table 16. Modal analysis results.

\begin{tabular}{lccc}
\hline \multicolumn{1}{c}{ POP Core Samples } & Aggregate vol\% & Matrix vol\% & Voids vol\% \\
\hline 15-Top & $59 \pm 5$ & $37 \pm 5$ & $4 \pm 2$ \\
15 -Bottom & $61 \pm 5$ & $33 \pm 5$ & $6 \pm 3$ \\
3-Top & $64 \pm 5$ & $31 \pm 5$ & $5 \pm 2$ \\
3-Bottom & $60 \pm 5$ & $36 \pm 5$ & $4 \pm 2$ \\
6-Top & $60 \pm 5$ & $35 \pm 5$ & $6 \pm 2$ \\
6-Bottom & $59 \pm 5$ & $39 \pm 5$ & $3 \pm 2$ \\
17-Top & $59 \pm 5$ & $38 \pm 5$ & $3 \pm 2$ \\
17-Bottom & $57 \pm 5$ & $40 \pm 5$ & $3 \pm 2$ \\
Mean & $60 \pm 2$ & $36 \pm 2$ & $4 \pm 1$ \\
& & & \\
\hline Baseline Cylinders & Aggregate vol\% & Matrix vol\% & Voids vol\% \\
\hline 8-Top & $56 \pm 5$ & $38 \pm 4$ & $6 \pm 2$ \\
8-Bottom & $62 \pm 5$ & $31 \pm 5$ & $6 \pm 2$ \\
7-Top & $60 \pm 4$ & $32 \pm 4$ & $8 \pm 2$ \\
7-Bottom & $56 \pm 5$ & $36 \pm 5$ & $8 \pm 3$ \\
Mean & $59 \pm 2$ & $34 \pm 2$ & $7 \pm 1$ \\
\hline
\end{tabular}




\section{SUMMARY}

The information and discussions in the preceding sections indicate that the latex-modified Rapid Set mortar met or exceeded the application and performance criteria specified in the test plan. ${ }^{6}$

The data indicate that the optimum BWCS barrier material compositions would be in the range 100 parts Rapid Set cement, 35 to 50 parts water, 15 parts Modifier A (latex solids), 200 to 300 parts concrete sand-ASTM C-33, and 0.4 to 0.7 parts citric acid.

The temperature maximum of $54^{\circ} \mathrm{C}$ during barrier material curing suggests that the rate of heat release by Rapid Set cement during curing is not sufficient to cause a safety issue during normal field applications.

The treatment of both cured laboratory and field drill core samples in several aqueous solutions showed no evidence of reaction with carbonate, sulfate, or field test site soil leachate. The water in the solutions decreased the compressive strength of the laboratory samples about $30 \%$ and the field test samples about $45 \%$. These values are typical of latex-modified mortar and concrete. The loss of strength is usually accompanied by water absorption by the latex and a very beneficial decrease in hydraulic conductivity of the material. ${ }^{5}$ The changes are usually reversible, that is, the sample strength returns, the latex shrinks, etc., when the water is lost.

The field observations show that the soil was moist and the slab was wet at the time of excavation, suggesting that the water content of the overlying soil was near or at water saturation during the curing period of the barrier material.

A single hairline crack was found in the buried test slab. The hairline crack is located strictly in the material of Test Run \#2 and terminates against the material of Test Run \#1 and Test Run \#3. The cause of the fracture is not apparent from available data. Virtually identical procedures and materials were used to produce a slab containing two stop-start joints during the BWCS visual test, ${ }^{8}$ but this slab did not fracture. The hydraulic conductivity of the material containing the fracture was low, $1.2 \times 10^{-5} \mathrm{~cm} / \mathrm{s}$.

The hydraulic conductivity measurements indicate that material in the overnight stop-start joint as well as the barrier materials in the BWCS buried Test Run \#2 exceed the EPA hydraulic conductivity requirements of $1 \times 10^{-7} \mathrm{~cm} / \mathrm{s}$. The material containing the stop-start joint had a hydraulic conductivity of $1.1 \times 10^{-8} \mathrm{~cm} / \mathrm{s}$, and the BWCS buried Test Run $\# 2$ barrier material had a hydraulic conductivity of about $1.6 \times 10^{-10} \mathrm{~cm} / \mathrm{s}$. These results are confirmed by the less precise field measurements of air permeability of $8.6 \times 10^{-7} \mathrm{~cm} / \mathrm{s}$ for the stop-start joint and $8.6 \times 10^{-9} \mathrm{~cm} / \mathrm{s}$ for the homogeneous barrier material.

The mechanical property measurements and petrographic analysis of the baseline materials prepared at the MTL provide a standard of comparison for similar measurements made on the BWCS barrier material. The data indicate that the two materials are usually noticeably different. In general, the baseline material has lower density $\left(1.93 \mathrm{~g} / \mathrm{cm}^{3}\right.$ versus $\left.2.19 \mathrm{~g} / \mathrm{cm}^{3}\right)$, much lower compressive strength (1,861 psi versus $5,241 \mathrm{psi}$ ), much lower modulus of elasticity $(403,000$ psi versus $2,960,000 \mathrm{psi})$, lower tensile strength (143 psi versus $200 \mathrm{psi}$ ), and slightly higher flexural strength (688 psi versus $604 \mathrm{psi}$ ). These differences are thought to be due primarily to three factors. The different methods used to mix the two materials may have resulted in different air contents (void space). The baseline material did not appear to cure to the same degree as the field materials over the same time periods, which may be due to, on one hand, differences in temperature and humidity during the curing process and, on the other, a difference in the order of introducing the components into the mixtures, particularly a possible reaction between the latex and citric acid during the preparation of the MTL baseline materials. 
Re-testing of the baseline barrier materials indicated that the order of mixing of the components can have a strong effect on the physical properties of the final barrier material. After 14 days, the re-tested baseline material was virtually identical to the BWCS Buried Test \#2 material.

The petrographic analysis showed that, within the precision of the modal analysis method, no segregation and/or separation of mixture components occurred during or after emplacement of the barrier materials in either the field tests or the baseline tests at the MTL.

A final point concerns the compressive strength of the stop-start joint. The data indicate that the joint has strength comparable to the homogeneous material, i.e., 5,014 psi versus 5,241 psi, the average compressive strength of the homogeneous BWCS Test Run \#2 barrier material. 


\section{RECOMMENDATIONS}

The results of the test program showed that the latex-modified Rapid Set mortar was, in many ways, an ideal material for the BWCS application. The test program also showed several areas of study and development, including estimates of long-term durability, which should be carried out before this material is used in the field.

The effect of water on the short- and long-term durability properties of the barrier material, particularly hydraulic conductivity and susceptibility to fracture formation, should be determined. This is suggested because the behavior of both laboratory-prepared samples and core samples from the field test materials showed that the specimens lost significant strength, and in some cases mass, due to exposure to water. The effects, both short and long term, of this change should be evaluated. Evaluations should include experiments to determine the long-term alteration mechanisms and the rate of alteration and mass loss and the effect, if any, on hydraulic conductivity and other properties. The decrease in compressive strength may be beneficial for the BWCS application as it probably also produces a decrease in brittleness, i.e., an increase in plasticity and a decrease in fracture formation in the barrier material. This hypothesis needs to be tested and the relationships with other properties of the material evaluated.

Closely related to the above recommendation is the suggestion that the limiting water content of the waste site soil be determined, which would allow set and cure of the barrier material. The results of the proposed work would indicate applications near or below the water table and in non-arid climates. This suggestion is prompted by the observation made during the baseline sample preparation that temperature and humidity apparently had a strong influence on barrier material setting time and properties.

The optimum barrier material composition to minimize or eliminate fracture formation should be determined. This suggestion comes from the observation of the hairline fracture that formed in BWCS Test Run \#2. The cause of the fracture is not apparent from available data. Virtually identical procedures and materials were used to produce a test slab containing two stop-start joints during the BWCS visual test, ${ }^{8}$ but this test slab did not fracture. Systematic work needs to be done to identify and eliminate the factors that cause cracking while not adversely affecting the required properties of the material.

The barrier material composition and emplacement procedure should be developed to optimize stopstart joint properties, particularly hydraulic conductivity and strength.

In general, the long-term durability of the material needs to be evaluated and, if necessary, the composition optimized for best performance. Two topics need particular attention. At present, no information is available to estimate the resistance of the barrier materials to biological degradation. Therefore systematic study of biological degradation needs to be carried out. A second aspect of longterm durability is the development of means to prevent mechanical stress and the resulting long- term development of fractures in the barrier material. An approach should be developed to optimize the material's resistance to stress and to also minimize the stress to which the material will be subjected.

Finally, before the material can be used in the field, the barrier material composition should be evaluated and optimized for application to the specific waste site. Waste site properties to be considered include, but are not limited to, waste composition, soil chemistry and water content, and site geology including seismic activity, climate, and other properties. 


\section{REFERENCES}

1. EPA, Resource Conservation and Recovery Act, Subtitle C, U.S. Environmental Protection Agency, 1989.

2. ASTM, Annual Book of ASTM Standards, American Society of Testing and Materials, current issue.

3. G. G. Loomis, D. N. Thompson, and J. H. Heiser, Innovative Subsurface Stabilization of Transuranic Pits and Trenches, INEL-95/0632, Idaho National Engineering Laboratory, 1995.

4. M. L. Allen, Latex Modified Grouts For In Situ Stabilization of Buried Transuranic/Mixed Waste, BNL-63199, Brookhaven National Laboratory, 1996.

5. V. S. Ramachandran, Concrete Admixtures Handbook, Noyes Publications, 2nd Ed., ISBN 8155 $13739,1995$.

6. J. Weidner and P. Shaw, Test Plan for Buried Waste Containment System Materials, INEEL/EXT-97-00221, Rev. 1, Idaho National Engineering and Environmental Laboratory, August 1997.

7. P. G. Shaw, In Situ Pretreatment and Solidification Agents for an Underground Waste Storage Tank, INEEL/EXT-97/001xx, Idaho National Engineering and Environmental Laboratory, August 1997.

8. RAHCO International $\circledast$, Test Report for Barrier Placement Proof-Of-Principle Test Barrier Waste Containment System Project, RAHCO2247-07159RAL, RAHCO International®, Spokane, Washington, 1997.

9. C. F. Knutson, D. O. Cox, K. J. Dooley, and J. B. Sisson, "Characterization of Low-Permeability Media Using Outcrop Measurements," SPE-26487, Proceedings of the 68th Annual Technical Conference of the Society of Petroleum Engineers, 1993, pp. 729-739.

10. A. L. Baehr and M. F. Hult, "Evaluation of Unsaturated Zone Air Permeability Through Pneumatic Tests," Water Resources Research, Vol. 27, No. 10, 1991, pp. 2605-2617.

11. J. W. Massmann, "Applying Groundwater Flow Models in Vapor Extraction System Design," Journal of Environmental Engineering, Vol. 115, No. 1, 1989, pp. 129-149.

12. J. Weidner, J. Sondrup, T. Kaser, and W. Downs, Vapor Port Permeability, ER-VVED-101, EG\&G Idaho, Inc., Idaho Falls, ID, 1992, 25 pp.

13. P. M. Kearl, R. J. Zinkl, J. J. Dexter, and T. Cronk, "Air Permeability Measurements of the Unsaturated Bandelier Tuff near Los Alamos, New Mexico," Journal of Hydrology, 117, 1990, pp. $† 225-240$.

14. M. J. Horslev, Time Lag and Soil Permeability in Groundwater Observations, Bulletin 36, Waterways Experimental Station Corps of Engineers, U.S. Army, Vicksburg, MS, 1951.

15. J. C. Griffiths, Scientific Method in Analysis of Sediments, McGraw-Hill Book Co., 1967, 508 pp.

16. M. Jones, "Automatic Image Analysis," Chapter 4, Physical Methods in Determinative Mineralogy, J. Zussman (ed.), Academic Press, 1977, 720 pp. 
Appendix A

Equipment 


\section{Appendix A}

\section{Equipment}

\section{Laboratory}

1. Balance-

Metlar, PC4400

2. Microscope-

3. Camera-

4. Compressive strength-

5. Viscometer-

6. Drying Oven-

Bosch \& Lomb, Stereo-Zoom 7

Polaroid, Microcam

ECS G-900 Versa-Loader, with a Soil Cement Test

Digital Readout Set, $10^{4}$-lb capacity.

Brookfield Digital Viscometer, Model DVII+, with a Brookfield Helipath Stand and a T-bar Spindle.

Blue M

\section{Field Data andAir Permeability}

1. Datalogger -

2. Portable Computer -

3. Differential Pressure Transducer-

4. Atmospheric Pressure Transducer-

5. Thermocouple-

6. Flow Transducer-

7. Field Camera

Cambell Scientific Inc., Model 21X

Compact Portable Three

Druck, Model PDCR120, 0-25 psi

Setra, Model 270, 600-1100 mbar

Type $\mathrm{K}$, chromel-alumel

Hastings, Model HFM-200L, 0-30 sccm

Canon F-1, Vivitar 55mm Macro lens

\section{Hydraulic Conductivity}

1. Permeameter-

Flexible wall

\section{Petrographic Analysis}

1. Microscope-

Bosch and Lomb 10X, 20X, 40X, stereoscopic.

\section{Property}

1. Analytical balance, $\mathrm{kg}$ (O'HAUS) and $\mathrm{mg}$ (METTLER) range

2. 250-mL polyethylene bottles

3. $\mathrm{pH}$ meter (Orion)

4. Slump test cone and tray (Slump Test Set CT-225, ELE International)

5. Plastic and cardboard molds

6. Multi-station variable speed stir plate and stir bars

7. Stainless steel spatula 
Appendix B

Baseline Sample Mixture \#3 


\section{Appendix B}

\section{Baseline Sample Mixture \#3}

The following information describes the preparation of a batch of latex-modified mortar on September 12,1997, and the mechanical properties of that batch. The batch preparation and testing were done in order to evaluate the effect of the order of mixing of the mortar components on the mechanical properties of the mortar. The work was prompted by the differences observed between the baseline samples and the samples taken from the BWCS field test material (see Section 5).

The batch composition was as nearly as possible like the original baseline, Mixtures \#1 and \#2, prepared at the CFA Materials Testing Laboratory (see Section 5.1.3). The batch was prepared in the same facility using the same equipment and material (see Section 5.1.2) as the original baseline mixtures. Air dry concrete sand (ASTM-33) was placed into the mixing machine. The required citric acid was dissolved in the water and the solution added to the sand. After about 3 minutes of mixing, Rapid Set cement was added. The required amount of latex, Dow Chemical Modifier A, was added to the batch after about 30 seconds of mixing and was further mixed for about 3 minutes, producing a very lumpy, stiff, plastic material. About $3.3 \mathrm{lb}$ of water were then added and mixed an additional 4 minutes. The mixture was poured into the required $6 \times 12$-in. and $3 \times 6$-in. molds and allowed to set. Slump, measured at the same time, was 8 in. Initial set time was estimated to be about 25 minutes. The estimate was made by manually pressing a 3/8-in. diameter plastic cylinder into the surface of mix material in a $6 \times 12$-in. mold and judging the resistance to penetration. The estimate was based on extensive experience making identical measurements using a hand-held penetrometer. The batch materials set and cured at ambient temperature and humidity.

The following data indicate that the material described here is virtually identical to the BWCS field test samples (see Section 5.1.4) when the difference in age is taken into account. The great disparity between the material described here and the previous baseline samples (see Section 5.1.4) is due to the difference in the sequence of adding the component materials. Particularly, the citric acid and cement are mixed before the addition of the latex so that a premature reaction between the latex and citric acid cannot occur. The data indicate that the order of mixing the mixture components can greatly affect the properties of the cured product.

\section{Mixture Composition}

Mixture weight percent per 100 parts cement

$\begin{array}{lll}\text { Cement } & 22 & 100 \\ \text { Sand } & 66.4 & 302 \\ \text { Latex } & 3.15 & 14.3 \\ \text { Total water } & 8.31 & 37.7 \\ \text { Citric acid } & 0.09 & 0.4\end{array}$

\section{Density: ASTM C-642}

MTL BWCS Batch 3 material $6 \times 12$-in. cylinders at 14 days after preparation

$\begin{array}{cc}\text { Specimen } & \mathrm{lb} / \mathrm{ft}^{3} \\ 1 & \\ 2 & 127.7 \\ & 128.2\end{array}$




\section{Compressive Strength: ASTM C-39}

MTL BWCS Batch \#3 material 3 x 6-in. cylinders

Specimen psi Sample age (days)

3

1,938

3

$4 \quad 3,565$

$5 \quad 3,945$

5

5

6

7

4,170

4,385

8

8

$\begin{array}{lll}8 & 5,020 & 10 \\ 9 & 4,810 & 10\end{array}$

10

5,163

5,347

14

14

\section{Tensile (Splitting Strength): ASTM C-642}

MTL BWCS Batch \#3 material 6 x 12-in. cylinders measured 11 days after mixture preparation Specimen psi

$\begin{array}{ll}12 & 445 \\ 13 & 422\end{array}$

\section{Modules of Elasticity: ASTM C-469}

MTL BWCS Batch \#3 material 6 x 12-in. cylinders measured 11 days after mixture preparation Specimen psi

$14 \quad 1,930,000$

$15 \quad 2,460,000$ 